\title{
Synthesis of Two-Dimensional Nb1.33C (MXene) with Randomly Distributed Vacancies by Etching of the Quaternary Solid Solution (Nb2/3Sc1/3)2AIC MAX Phase
}

J oseph Halim, J ustinas Palisaitis, J un Lu, J immy Thörnberg, Moon E. J., Precner M., Per Eklund, Per O. Å. Persson, Barsoum M. W. and J ohanna Rosén

The self-archived postprint version of this journal article is available at Linköping University Institutional Repository (DiVA):

http:// urn.kb.se/ resolve?urn=urn:nbn:se:liu:diva-151667

N.B.: When citing this work, cite the original publication.

Halim, J ., Palisaitis, J., Lu, J ., Thörnberg, J ., E. J., M., M., P., Eklund, P., Persson, P. O. Å., M. W., B., Rosén, J ., (2018), Synthesis of Two-Dimensional Nb1.33C (MXene) with Randomly Distributed Vacancies by Etching of the Quaternary Solid Solution (Nb2/3Sc1/3)2AlC MAX Phase, ACS Applied Nano Materials, 1(6), 2455-2460. https:// doi.org/ 10.1021/ acsanm.8b00332

Original publication available at:

https:// doi.org/ 10.1021/ acsanm.8b00332

Copyright: American Chemical Society http:// pubs.acs.org/ 


\title{
Synthesis of two-dimensional $\mathrm{Nb}_{1.33} \mathrm{C}$ (MXene) with
}

\author{
randomly distributed vacancies by etching of the
}

\section{quaternary solid solution $\left(\mathrm{Nb}_{2 / 3} \mathrm{Sc}_{1 / 3}\right)_{2} \mathrm{AlC} \mathrm{MAX}$}

\author{
phase
}

J. Halim, ${ }^{a}$ J. Palisaitis, ${ }^{a}$ J. Lu, ${ }^{a}$ J. Thörnberg, ${ }^{a}$ E.J. Moon, ${ }^{b}$ M. Precner,${ }^{c}$ P. Eklund, P. O. A. Persson, ${ }^{a}$ M. W. Barsoum, ${ }^{b}$ and J. Rosen ${ }^{a, *}$

\begin{abstract}
AUTHOR ADDRESS
a Thin Film Physics, Department of Physics, Chemistry, and Biology (IFM), Linkoping, Sweden

${ }^{\mathrm{b}}$ Department of Materials Science and Engineering, Drexel University, PA 19104, USA

${ }^{\mathrm{c}}$ Institute of Electrical Engineering, Slovak Academy of Sciences, 84104 Bratislava, Slovak

Republic
\end{abstract}

KEYWORDS

Transition metal carbide; 2D material; synthesis; MXene; electronic properties 


\section{ABSTRACT}

Introducing point defects in two dimensional, 2D, materials can alter or enhance their properties. Here, we demonstrate how etching a laminated $\left(\mathrm{Nb}_{2 / 3} \mathrm{Sc}_{1 / 3}\right)_{2} \mathrm{AlC} \mathrm{MAX}$ phase (solid solution) of both the $\mathrm{Sc}$ and $\mathrm{Al}$ atoms, results in a $2 \mathrm{D} \mathrm{Nb}_{1.33} \mathrm{C}$ material (MXene) with a large number of vacancies and vacancy clusters. This method is applicable to any quaternary, or higher, MAX phase wherein one of the transition metals is more reactive than the other and could be of vital importance in applications such as catalysis and energy storage. We also report, for the first time, on the existence of $\left(\mathrm{Nb}_{2 / 3} \mathrm{Sc}_{1 / 3}\right)_{3} \mathrm{AlC}_{2}$ and $\left(\mathrm{Nb}_{2 / 3} \mathrm{Sc}_{1 / 3}\right)_{4} \mathrm{AlC}_{3}$ phases. 
Two-dimensional (2D) materials have shown great promise for many applications. ${ }^{1-6}$ The reduced dimension leads to an increase in the surface to volume ratio, and can fundamentally alter the chemical, optical and electronic properties of a material. The properties can be altered further, either chemically via surface functionalization, ${ }^{7}$ intercalation ${ }^{8}$ or structurally, by introducing defects. $^{8-9}$

About 7 years ago, a new class of 2D materials based on transition metal carbides and/or nitrides (MXenes) was discovered. ${ }^{10-11}$ MXenes are mainly produced by etching the $M_{n+1} A X_{n}$ (MAX) phases or related ternary phases. ${ }^{12}$ The MAX phases are a family of hexagonal, layered ternary transition metal carbides and/or nitrides where $\mathrm{M}$ stands for an early transition metal, A stands for group 13 and 14 elements, X stands for carbon and/or nitrogen and $n=1$, 2, or $3 .{ }^{13}$ Various acidic solutions, containing fluoride ions are used to selectively etch the A layers (either $\mathrm{Al}$ or $\mathrm{Ga}$ ) and convert MAX to MXene. ${ }^{10,14-17}$ The A layers are replaced with oxygen, hydroxyl and/or fluoride surface terminating (T) groups. ${ }^{18}$ MXenes show promise for a large host of applications including batteries, supercapacitors, transparent conducting electrodes, catalytic and photocatalytic applications, water treatment, electromagnetic shielding, gas sensors and biosensors. ${ }^{19-25}$

MXene properties can be tuned in at least three ways that involve either altering their: i) composition, ii) surface terminations, $\mathrm{T}_{\mathrm{x}}$ and/or, iii) structure/morphology. The composition can be changed by e.g. forming solid solutions though alloying on the $\mathrm{M}-{ }^{26}$ and/or $\mathrm{X}^{-27}$ sites in the parent MAX phase. The quaternaries, $\left(\mathrm{Nb}_{0.8}, \mathrm{Ti}_{0.2}\right)_{4} \mathrm{C}_{3} \mathrm{~T}_{\mathrm{x}}$ and $\left(\mathrm{Nb}_{0.8}, \mathrm{Zr}_{0.2}\right)_{4} \mathrm{C}_{3} \mathrm{~T}_{\mathrm{x}}{ }^{28}$ are examples 
in which M-site MAX solid solution phases were etched to produce their MXenes. $\mathrm{Ti}_{3} \mathrm{CNT}_{\mathrm{x}}$ is an example of a MXene with X-site solid solution. ${ }^{11}$ Altering the surface terminations can be made by chemical treatment such as alkali treatment and/or post-etching heat treatment to remove $\mathrm{F}$ terminations. ${ }^{29-30}$

Quite recently quaternary $n=1$, or 211, MAX phases with in-plane chemical ordering were discovered. These phases were labeled $i$-MAX because of the ordering of two different $\mathrm{M}$ elements, in a 2:1 ratio, in the basal planes. The first example was $\left(\mathrm{Mo}_{2 / 3} \mathrm{Sc}_{1 / 3}\right)_{2} \mathrm{AlC} .{ }^{31}$ When this phase was etched both the $\mathrm{Al}$ and Sc atoms were removed and a MXene - $\mathrm{Mo}_{1.33} \mathrm{CT}_{\mathrm{z}}$ wherein the vacancies were ordered - was produced. This vacancy-ordered 2D material exhibited a three orders of magnitude higher electrical conductivity and a $65 \%$ higher capacitance when used as a supercapacitor electrode compared to $\mathrm{Mo}_{2} \mathrm{CT}_{\mathrm{x}}$. Furthermore, an ultrathin flexible $\mathrm{Mo}_{1.33} \mathrm{CT}_{\mathrm{x}} /$ polymer film showed promising performance as a solid-state supercapacitor. ${ }^{32}$ Since then, other $i$-MAX phases have been theoretically predicted and synthesized such as $\left(\mathrm{V}_{2 / 3} \mathrm{Zr}_{1 / 3}\right)_{2} \mathrm{AlC},\left(\mathrm{Mo}_{2 / 3} \mathrm{Y}_{1 / 3}\right)_{2} \mathrm{AlC}$ and $\left(\mathrm{Cr}_{2 / 3} \mathrm{Sc}_{1 / 3}\right)_{2} \mathrm{AlC}^{33-34} \mathrm{~A}$ characteristic feature of the $i$-MAX phases is that the minority $\mathrm{M}$ elements extends from the $\mathrm{M}$ towards the $\mathrm{Al}$ layers, with a structure described by a $(\mathrm{C} 2 / \mathrm{c})$ or $(\mathrm{C} 2 / \mathrm{m})$ symmetry. ${ }^{32}$ This is opposed to the traditional MAX phase of $P 6_{3} / m m c$ symmetry, which describes most quaternary 211 MAX phases (solid solutions) realized.

A large majority of MXene work to date has been carried out on $\mathrm{Ti}_{3} \mathrm{C}_{2} \mathrm{~T}_{\mathrm{x}}$. There are others, however. Recently, $\mathrm{Nb}_{2} \mathrm{CT}_{\mathrm{x}}$ flakes have shown promising performance for photothermal cell ablation and as a photocatalyst for hydrogen evolution in addition to previously reported results for energy storage applications. ${ }^{35-38}$ These reports were the impetus for this work, together with our recent discovery of a quaternary $\mathrm{i}$-MAX phase in which the minority M element - Sc in this case - was readily etched. 

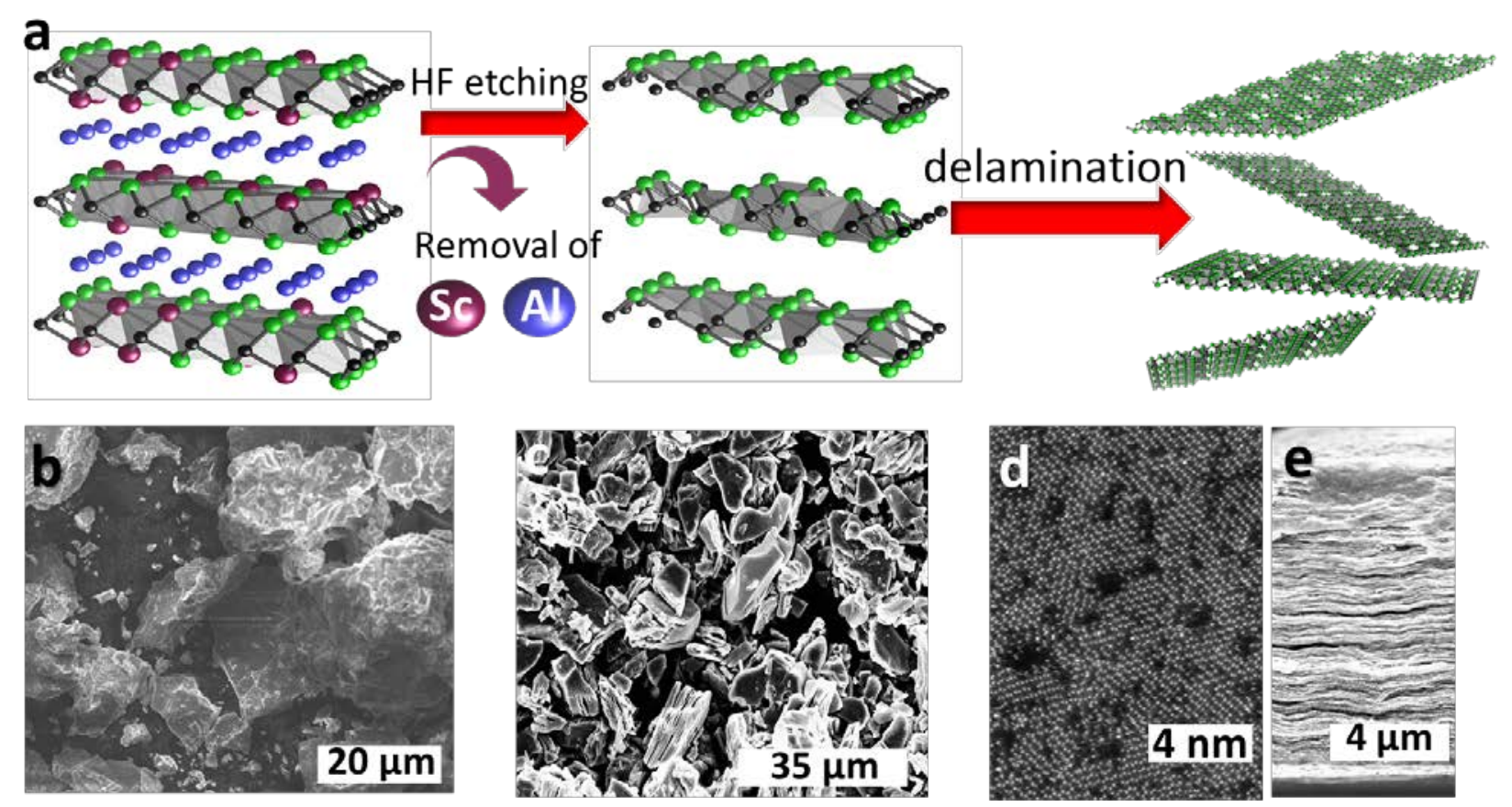

Figure 1. (a) Schematic showing synthesis, etching and delamination of $\left(\mathrm{Nb}_{2 / 3} \mathrm{Sc}_{1 / 3}\right)_{2} \mathrm{AlC}$ to form $\mathrm{Nb}_{1.33} \mathrm{CT}_{\mathrm{x}}$. Green, black, red and blue atoms represent Nb, C, Sc, and Al, respectively, (b) SEM micrograph of $\left(\mathrm{Nb}_{2 / 3} \mathrm{Sc}_{1 / 3}\right)_{2} \mathrm{AlC}$ powders, (c) SEM micrograph of multi-layered $\mathrm{Nb}_{1.33} \mathrm{CT}_{\mathrm{x}}$ powders, and (d) STEM micrograph of a single $\mathrm{Nb}_{1.33} \mathrm{CT}_{\mathrm{x}}$ flake and (e) SEM micrograph of crosssection of free-standing film made from delaminated $d-\mathrm{Nb}_{1.33} \mathrm{CT}_{\mathrm{x}}$.

First, we synthesized the new quaternary MAX solid solution, $\left(\mathrm{Nb}_{2 / 3} \mathrm{Sc}_{1 / 3}\right)_{2} \mathrm{AlC}$, wherein the M elements $\mathrm{Nb}$ and Sc are not ordered. We then selectively etched both $\mathrm{Al}$ and Sc atoms to produce $\mathrm{Nb}_{1.33} \mathrm{CT}_{\mathrm{x}}$, with randomly distributed vacancies and vacancy clusters. A schematic of our approach is shown in Figure 1a. In principle this method should be applicable to any quaternary MAX phase in which the minority M-element is etchable. 


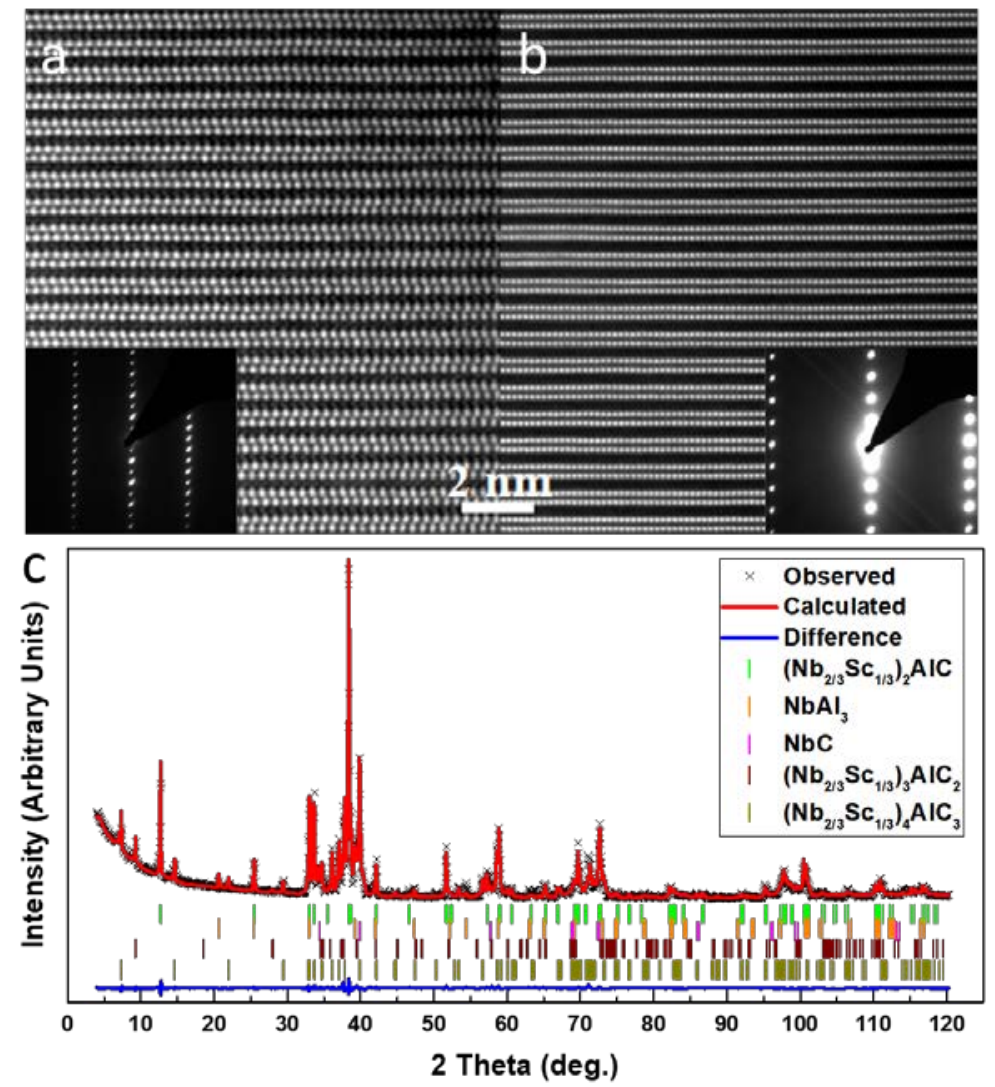

Figure 2. (a) STEM micrograph with SAED of $\left(\mathrm{Nb}_{2 / 3} \mathrm{Sc}_{1 / 3}\right)_{2} \mathrm{AlC}$ in [11 $\left.\overline{2} 0\right]$ zone axis, b) same as a but in [10 $\overline{1} 0]$ zone axes, and (c) XRD patterns indexed to $\left(\mathrm{Nb}_{2 / 3} \mathrm{Sc}_{1 / 3}\right)_{2} \mathrm{AlC}$ powder showing observed pattern (black crosses), Rietveld generated pattern (red line) and the difference between the two (blue line). The green, orange, purple, violet and olive ticks below the pattern represent the peak positions of $\left(\mathrm{Nb}_{2 / 3} \mathrm{Sc}_{1 / 3}\right)_{2} \mathrm{AlC}, \mathrm{NbAl}_{3}, \mathrm{NbC},\left(\mathrm{Nb}_{2 / 3} \mathrm{Sc}_{1 / 3}\right)_{3} \mathrm{AlC}_{2}$, and $\left(\mathrm{Nb}_{2 / 3} \mathrm{Sc}_{1 / 3}\right)_{4} \mathrm{AlC}_{3}$ phases, respectively.

The quaternary solid solution, $\left(\mathrm{Nb}_{2 / 3} \mathrm{Sc}_{1 / 3}\right)_{2} \mathrm{AlC}$, was synthetized by reacting the elemental powders, $\mathrm{Nb}, \mathrm{Sc}, \mathrm{Al}$, and, $\mathrm{C}$ in a molar ratio of 4/3:2/3:1:1 at $1400{ }^{\circ} \mathrm{C}$ for $2 \mathrm{~h}$ in flowing $\mathrm{Ar}$ (processing details can be found in Supporting Information). The crystal structure is shown in leftmost panel in Figure 1a. Figures 1b and 1c show Scanning Electron Microscope, SEM, images of the $\left(\mathrm{Nb}_{2 / 3} \mathrm{Sc}_{1 / 3}\right)_{2} \mathrm{AlC}$ powders before, and after, etching, respectively. Figure $1 \mathrm{~d}$ shows a typical 
Scanning Transmission Electron Microscope, STEM, image of a single $\mathrm{Nb}_{1.33} \mathrm{CT}_{\mathrm{x}}$ flake showing vacancies and vacancy clusters. The removal of Sc atoms was confirmed by electron energy loss spectroscopy analysis (see Supplementary Information, Figure S1). Figure 1e shows a crosssectional SEM image of a free standing thin film made by filtering delaminated $\mathrm{Nb}_{1.33} \mathrm{CT}_{\mathrm{x}}$ flakes.

The STEM images, shown in Figure 2,a and b, show the typical MAX phase layered structure. ${ }^{13}$ The MAX phase identification is further confirmed by the selected area electron diffraction, SAED, (inset in Figure 2a,b). Rietveld refinement analysis of a powder the X-ray diffraction (XRD) pattern (Figure 2c) was used to quantify the various phases present. According to Rietveld analysis (refinement details can be found in the Supplementary Information), the sample contained the following phases: $\left(\mathrm{Nb}_{2 / 3} \mathrm{Sc}_{1 / 3}\right)_{2} \mathrm{AlC}, \mathrm{NbAl}_{3}, \mathrm{NbC},\left(\mathrm{Nb}_{2 / 3} \mathrm{Sc}_{1 / 3}\right)_{3} \mathrm{AlC}_{2}$, and $\left(\mathrm{Nb}_{2 / 3} \mathrm{Sc}_{1 / 3}\right)_{4} \mathrm{AlC}_{3}$ with weight \% of: 68(2) wt.\%, 10.1(4) wt.\%, 17.4(4) wt.\%, 2.5(3) wt.\%, and 2.0(2) wt. \%, respectively. When all the phases were considered, the $\chi^{2}$ value was 8.78 . Note that the powder showed evidence for $\left(\mathrm{Nb}_{2 / 3} \mathrm{Sc}_{1 / 3}\right)_{\mathrm{n}+1} \mathrm{AlC}_{\mathrm{n}}$, with $\mathrm{n}=1,2$ and 3 .

For the main phase $\left(\mathrm{Nb}_{2 / 3} \mathrm{Sc}_{1 / 3}\right)_{2} \mathrm{AlC}$, since $\mathrm{Nb}$ and $\mathrm{Sc}$ are randomly distributed in transition metal position, the quaternary MAX phase retains the $P 6_{3} / m m c$ symmetry of ternary MAX phases. The $a$ and $c$ lattice parameters were calculated to be 3.12915(5) $\AA$ and 13.9736(3) $\AA$, respectively, which agree with those obtained from STEM and SAED. These lattice parameters are slightly larger than those of $\mathrm{Nb}_{2} \mathrm{AlC}(a=3.096-3.126 \AA$ and $c=13.804-13.888 \AA) .{ }^{39}$ The difference can be ascribed to the larger metallic radius of Sc (160 pm) compared to $\mathrm{Nb}(145 \mathrm{pm}) .{ }^{40}$ Similarly, and likely for the same reason, the lattice parameters of $\left(\mathrm{Nb}_{2 / 3} \mathrm{Sc}_{1 / 3}\right)_{4} \mathrm{AlC}_{3}(a=3.1855(5) \AA$ and $c=$ 23.878(6) $\AA$ ) are slightly larger than those of $\mathrm{Nb}_{4} \mathrm{AlC}_{3}(a=3.1296 \AA$ and $c=24.1208 \AA) .{ }^{41}$ Despite the fact that to date $\mathrm{Nb}_{3} \mathrm{AlC}_{2}$ has not been experimentally realized, the introduction of Sc appears 
to stabilize the $\left(\mathrm{Nb}_{2 / 3} \mathrm{Sc}_{1 / 3}\right)_{3} \mathrm{AlC}_{2}$ solid solution. This has been also reported for other 312 phases, where a second M element stabilizes an otherwise unstable 312 phase. ${ }^{42-43}$

According to Energy Dispersive X-ray Spectroscopy (EDS) of individual MAX phase particles assumed to be $\left(\mathrm{Nb}_{2 / 3} \mathrm{Sc}_{1 / 3}\right)_{2} \mathrm{AlC}$, the $\mathrm{Nb}: \mathrm{Sc}$ :Al atomic ratio was 1.2:0.8:1.0 (details of EDS analysis can be found in Supporting Information). From the Rietveld refinment of the $\mathrm{Nb}$ and $\mathrm{Sc}$ occupancies in the same phase, the $\mathrm{Nb}: \mathrm{Sc}$ atomic ratio was found to be 1.38:0.62. It is thus reasonable to conclude the $\mathrm{Nb}: \mathrm{Sc}$ ratio is between 1.2:0.8 and 1.4:0.6. At 2:1.33 to 2:0.86, respectively, these ratios bracket the nominal ratio of 2:1.

The MXene synthesis details can be found in the Supporting Information. Immersing $\left(\mathrm{Nb}_{2 / 3} \mathrm{Sc}_{1 / 3}\right)_{2} \mathrm{AlC}$ powders in $48 \%$ conc. hydrofluoric acid (HF) at room temperature, $\mathrm{RT}$, for $30 \mathrm{~h}$ resulted in selective etching of the majority of both of the $\mathrm{Al}$ and Sc atoms, creating $\mathrm{Nb}_{1.33} \mathrm{CT}_{\mathrm{x}}$ multilayers, MLs, (Figure 1c). Clearly the Sc atoms are more reactive than the Nb, which is consistent with theoretical calculations that have shown that the Sc-C and C-Al bonds in $\mathrm{Sc}_{2} \mathrm{AlC}$ are of comparable strengths and both weaker than the $\mathrm{Nb}-\mathrm{C}$ or $\mathrm{Nb}-\mathrm{Al}$ bondsin $\mathrm{Nb}_{2} \mathrm{AlC} .{ }^{44}$

To obtain $\mathrm{Nb}_{1.33} \mathrm{CT}_{\mathrm{x}}$ monolayers, the $\mathrm{ML}$ powder was intercalated with tetrabutylammonium hydroxide $(\mathrm{TBAOH})$ in water following the procedure described by Naguib et al., ${ }^{45}$ followed by delamination in water by hand shaking, yielding $\mathrm{a} \approx 1 \mathrm{mg} / \mathrm{ml}$ suspension of, most probably, single MXene flakes in water. To produce a delaminated $d-\mathrm{Nb}_{2} \mathrm{CT}_{\mathrm{x}}$ suspension starting with $\mathrm{Nb}_{2} \mathrm{AlC}$, using the same method, the etching time had to be increased to $100 \mathrm{~h}$ compared to $30 \mathrm{~h}$ for $\left(\mathrm{Nb}_{2 / 3} \mathrm{Sc}_{1 / 3}\right)_{2} \mathrm{AlC}$ - yielding a colloidal suspension with a concentration of $<$ $0.5 \mathrm{mg} / \mathrm{ml}$. Hence, the introduction of Sc in the MAX phase improves yield and reduces etching time. 
When filtering the $\mathrm{Nb}_{1.33} \mathrm{CT}_{\mathrm{x}}$ and $\mathrm{Nb}_{2} \mathrm{CT}_{\mathrm{x}}$ suspensions, only the former formed flexible, freestanding films that were easy to handle. The latter formed a brittle film that could not be peeled off the filter membrane without breaking into small pieces. It is for this reason that no transport properties are reported for this compound.
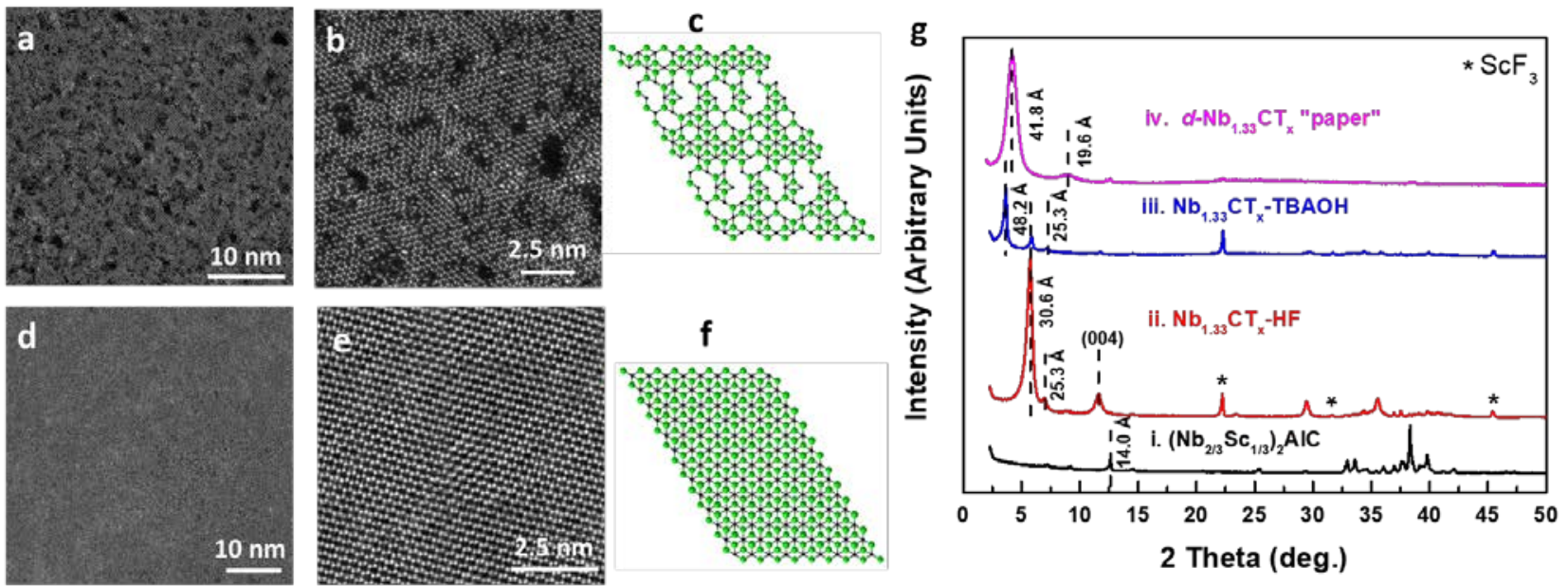

Figure 3. (a) Low magnification STEM micrograph of a $\mathrm{Nb}_{1.33} \mathrm{CT}_{\mathrm{x}}$ single flake, (b) same as (a) but at higher magnification, (c) top view schematic of single $\mathrm{Nb}_{1.33} \mathrm{CT}_{\mathrm{x}}$ sheet showing random vacancies and vacancy clusters. d) Low magnification STEM micrograph of $\mathrm{Nb}_{2} \mathrm{CT}_{\mathrm{x}}$ single flake, (e) same as (d) but at higher magnification, (f) top view schematic of single $\mathrm{Nb}_{2} \mathrm{CT}_{\mathrm{x}}$ sheet and, (g) XRD patterns of, i $\left(\mathrm{Nb}_{2 / 3} \mathrm{Sc}_{1 / 3}\right)_{2} \mathrm{AlC}$, ii. $\mathrm{Nb}_{1.33} \mathrm{CT}_{\mathrm{x}}-\mathrm{HF}$ which is that of multilayers after $\mathrm{HF}$ etching of $\left(\mathrm{Nb}_{2 / 3} \mathrm{Sc}_{1 / 3}\right)_{2} \mathrm{AlC}$ powders, iii. $\mathrm{Nb}_{1.33} \mathrm{CT}_{\mathrm{x}}-\mathrm{HF}-\mathrm{TBAOH}$ which is $\mathrm{Nb}_{1.33} \mathrm{CT}_{\mathrm{x}}$ after intercalation with TBAOH, and, iv. d-Nb ${ }_{1.33} \mathrm{CT}_{\mathrm{x}}$ film obtained by filtering a suspension of delaminated $\mathrm{Nb}_{1.33} \mathrm{CT}_{\mathrm{x}}$ (Figure 1e). Peaks annotated by asterisks correspond to $\mathrm{ScF}_{3}$ which is a residue of etching. 
A typical morphology of a $\mathrm{Nb}_{1.33} \mathrm{CT}_{\mathrm{x}}$ single flake can be seen in the STEM images in Figure 3a,b and can be compared to the schematic shown in Figure 3c. The flakes contain vacancies and vacancy clusters ranging in size between 0.1 and $2 \mathrm{~nm}$, resulting from the removal of the Sc atoms. The vacancies' areal coverage varied from $20 \%$ to $35 \%$ depending on the area imaged (see Supplementary Information Figure S2). STEM images of $\mathrm{Nb}_{2} \mathrm{CT}_{\mathrm{x}}$ single flakes, on the other hand, are shown in Figure 3d,e. In this case, the MXene layers, shown schematically in Figure 3f, are quite visibly less defective. The XRD patterns of the etched material (Figure 3g) show the typical increase in the interlayer spacing, denoted as $d_{c / 2}$, (becuase it is $1 / 2$ the $c-L P$ of the (002) parent MAX) to that of the parent phase, (compare Figures 3g-i and ii). This is typical of the MAX to MXene conversion and reflects the substitution of $\mathrm{Al}$ with surface terminations of $-\mathrm{O},-\mathrm{OH}$ and/or -F and multiple water layers. ${ }^{45-46}$ No residual peaks of the parent phase are present after etching indicating a complete MAX to MXene conversion. However, peaks corresponding to $\mathrm{ScF}_{3}$, denoted by asterisks, were present. After TBAOH intercalation, $\mathrm{d}_{\mathrm{c} / 2}$ increases to $24.1 \AA$ (Figure 3g-iii) reflecting the intercalation of the $\mathrm{TBA}^{+}$ions and more water molecules. After filtering the suspension to form a free-standing film (Figure $3 g-i v) \mathrm{d}_{\mathrm{c} / 2}$ is reduced to $20.9 \AA$ presumably due to the removal of some of the water molecules and possibly $\mathrm{TBA}^{+}$ions. 

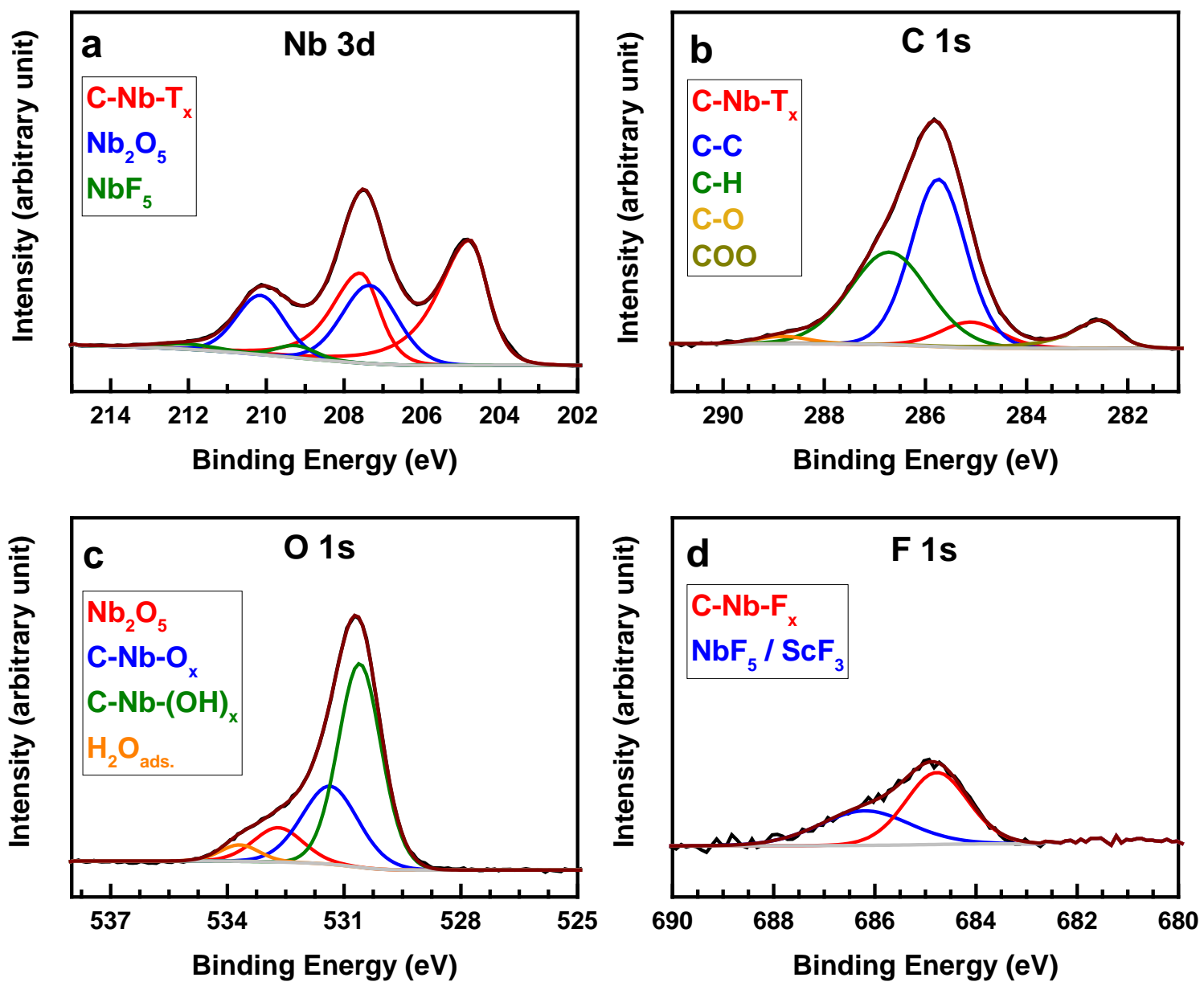

Figure 4. XPS spectra of $d-\mathrm{Nb}_{1.33} \mathrm{CT}_{\mathrm{x}}$ film for, (a) Nb 3d, (b) C 1s, (c) O 1s, and (d) F 1s regions. Color coded fitting peaks represent various assigned species (See Table S4).

High-resolution XPS spectra, with peak fits of a $d-\mathrm{Nb}_{1.33} \mathrm{CT}_{\mathrm{x}}$ filtered film are shown in Figures 4a-d for Nb 3d, C 1s, O 1s, and F 1s regions, respectively. The peak fitting results and the elemental compositions extracted from the high-resolution spectra can be found in Supporting Information. Based on the extracted atomic percentage of $\mathrm{Nb}, \mathrm{C}, \mathrm{O}$, and $\mathrm{F}$ and the fraction of each species solely related to the 2D flakes, the chemical formula that best describes $d-\mathrm{Nb}_{1.33} \mathrm{CT}_{\mathrm{x}}$ is $\mathrm{Nb}_{1.33} \mathrm{CO}_{1.7}(\mathrm{OH})_{0.6} \mathrm{~F}_{0.2 \cdot} \cdot 0.2 \mathrm{H}_{2} \mathrm{O}$, while that for $d-\mathrm{Nb}_{2} \mathrm{CT}_{\mathrm{x}}$ is $\mathrm{Nb}_{2} \mathrm{CO}(\mathrm{OH})_{0.6} \mathrm{~F}_{0.1} \cdot 0.3 \mathrm{H}_{2} \mathrm{O}-0.3 \mathrm{~N}$. (The $\mathrm{C}$ peak associated with MXene was used as the reference with base, error $< \pm 0.1$ ). The XPS 
results for $d-\mathrm{Nb}_{2} \mathrm{CT}_{\mathrm{x}}$ can be found in Supporting Information. The nitrogen, $\mathrm{N}$, component originates from the intercalated TBAOH, a component that was not possible to extract from the $d$ $\mathrm{Nb}_{1.33} \mathrm{CT}_{\mathrm{x}}$ flakes due to the overlap between the $\mathrm{N} 1 \mathrm{~s}$ and $\mathrm{Sc} 2 \mathrm{p}$ peaks (Figure S3b). it is clear that the -O is the dominant termination for both compounds. Interestingly it is $>1.5$ times higher in $d$ $\mathrm{Nb}_{1.33} \mathrm{CT}_{\mathrm{x}}$ compared to $d-\mathrm{Nb}_{2} \mathrm{CT}_{\mathrm{x}}$. The amounts of $-\mathrm{OH}$ and $-\mathrm{F}$, are comparable in both samples. Note that the fraction of the -F surface terminations for both compounds is low which is common for MXenes treated with TBAOH. ${ }^{45-46}$ At 2.5, the total number of termination moles of for $d$ $\mathrm{Nb}_{1.33} \mathrm{CT}_{\mathrm{x}}$, is 0.5 higher than the theoretical value of 2 obtained when all surface sites are filled. ${ }^{47}$ This suggests that some of the surface terminations may very well reside in the vacancies that result from the removal of the Sc atoms and are thus, strictly speaking, no longer terminations. The total moles of terminations for $d-\mathrm{Nb}_{2} \mathrm{CT}_{\mathrm{x}}$, excluding $\mathrm{N}$, is 1.7 , which is less than 2 . 

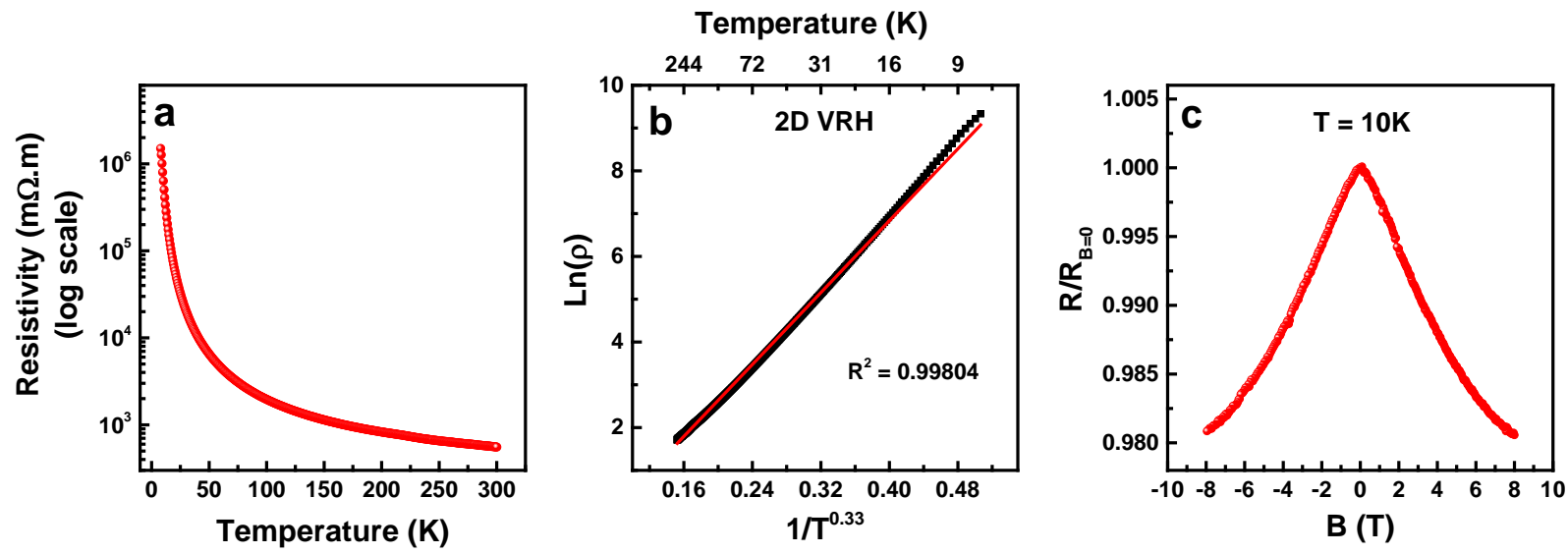

Figure 5. Electronic transport characteristics of $d-\mathrm{Nb}_{1.33} \mathrm{CT}_{\mathrm{x}}$ film on temperature and magnetic field.

(a) Log of resistivity, $\rho$, vs. temperature in 7 to $300 \mathrm{~K}$ temperature range, (b) $\rho$ vs. $1 / \mathrm{T}^{1 / 3}$ in the 7 to $300 \mathrm{~K}$ temperature range assuming 2D variable range hopping (VRH) conduction model and, (c) magnetoresistance at $10 \mathrm{~K} . \mathrm{R}_{\mathrm{B}=0}$ refers to resistance in the absence of magnetic field.

A semi-log plot of the resistivity, $\rho$, vs. temperature, $\mathrm{T}$, of a $22 \mu \mathrm{m}$ thick $d-\mathrm{Nb}_{1.33} \mathrm{CT}_{\mathrm{x}}$ film is shown in Figure 5a. The details of the measurements can be found in the Supporting Information. As the temperature decreases from $300 \mathrm{~K}$ to $7 \mathrm{~K}$, $\rho$ increases from 0.556 to $1500 \Omega$.m. To shed more light on the transport mechanism, the $\rho$ data in the 7 to $300 \mathrm{~K}$ temperature range were fitted to several models, including 2D, 3D and the Efros-Shklovskii, E-S, variable range hopping, VRH, simple thermal activation and power-law (non-exponential) models. The fitting results (Figure 5b and Figure S5) clearly eliminate the latter two (Figure S5). The same results, however, cannot differentiate between the various VRH models; the $\mathrm{R}^{2}$ for 2D, E-S and 3D VRH models are comparable, 0.9980, 0.9978 and 0.9964 , respectively. Figure 5b plots the results for the most likely model, viz. 2D VRH, the other fits for the other models can be found in Figure S5. Similar behavior has been reported for other MXene films such as $\mathrm{Mo}_{2} \mathrm{CT}_{\mathrm{x}},{ }^{46} \mathrm{Mo}_{2} \mathrm{TiC}_{2} \mathrm{~T}_{\mathrm{x}}$ and $\mathrm{Mo}_{2} \mathrm{Ti}_{2} \mathrm{C}_{3} \mathrm{~T}_{\mathrm{x}}{ }^{48}$ 
Magnetoresistance (MR) measurements - performed at $10 \mathrm{~K}$ - showed a negative MR, which is in contradistinction with MR measurements on other MXene compounds exhibiting the VRH mechanism. ${ }^{46,48}$ However, other disordered materials showing VRH, such as $\operatorname{In}_{2} \mathrm{O}_{3-\mathrm{x}}$, and Si doped in GaAs have been reported to exhibit negative MRs. ${ }^{49-51}$ The negative MR for materials having VRH conduction mechanisms has been ascribed to several reasons such as quantum interference, Zeeman effect or localized magnetic moments. ${ }^{52}$ These comments notwithstanding, much more work - which is beyond the scope of this paper - is needed to obtain a deeper understanding of conduction in our films.

In conclusion, a facile, reproducible, relatively rapid method for producing random vacancies and vacancy clusters in MXenes is presented, where the minority $\mathrm{M}$ element in a quaternary solid solution MAX phase is concomitantly etched with the A-group element. Herein we synthesized $\left(\mathrm{Nb}_{2 / 3} \mathrm{Sc}_{1 / 3}\right)_{2} \mathrm{AlC}$ and selectively etched both the $\mathrm{Sc}$ and $\mathrm{Al}$ atoms to produce $\mathrm{Nb}_{1.33} \mathrm{CT}_{\mathrm{x}}$ with disordered vacancies. The presence of Sc in the quaternary MAX phase decreased the etching time from 100 to $30 \mathrm{~h}$ and increased the yield of delaminated flakes.

When $\mathrm{Nb}_{1.33} \mathrm{CT}_{\mathrm{x}}$ free-standing films were cooled from 300 to $7 \mathrm{~K}$, their resistivity increased from 0.556 to $1500 \Omega$.m. The suggested transport mechanism is VRH accompanied by a negative MR at $10 \mathrm{~K}$. Lastly, there is no reason this approach cannot be used to "dial-in" a controlled number of vacancies, as long as the parent solid solution MAX phase exists. The fact that the flakes with vacancies are less dense than their counterparts is also noteworthy when specific properties are sought. 


\section{ASSOCIATED CONTENT}

\section{Supporting Information.}

The Supporting Information is available free of charge.

Synthesis of materials, characterization techniques, XPS spectra and transport fitting. (PDF)

\section{AUTHOR INFORMATION}

Corresponding Author

* Email: johanna.rosen@liu.se

Author Contributions

J.H. synthetized the material, performed the XRD, XPS characterization and analysis. M.P. performed the transport measurements, M.P., E.J.M, and J.H. analyzed the transport data. J.T. performed the SEM and EDX characterization and analyzed the data. J.P. and J.L performed the STEM characterization and analyzed the data. P.P., M.W.B and J.R. supervised the research. All authors contributed in the preparation of the manuscript and in discussions. All authors have given approval to the final version of the manuscript.

\section{Notes}

The authors declare no competing financial interest.

\section{ACKNOWLEDGMENT}

We acknowledge support from the Swedish Foundation for Strategic Research (SSF) through the Synergy Grant FUNCASE, the Research Infrastructure Fellow RIF 14-0074, and from the Knut and Alice Wallenberg (KAW) Foundation for a Fellowship Grant, Project funding (KAW 
2015.0043), and for support to the Linköping Electron Microscopy Laboratory. The Swedish

Research council is gratefully acknowledged through Projects 642-2013-8020 and 621-2014-4890.

We also acknowledge the Swedish Government Strategic Research Area in Materials Science on

Functional Materials at Linköping University (Faculty Grant SFO-Mat-LiU No. 2009-00971).

\section{REFERENCES}

1. Mas-Balleste, R.; Gomez-Navarro, C.; Gomez-Herrero, J.; Zamora, F., 2D Materials: to Graphene and Beyond. Nanoscale 2011, 3, 20-30.

2. Fiori, G.; Bonaccorso, F.; Iannaccone, G.; Palacios, T.; Neumaier, D.; Seabaugh, A.; Banerjee, S. K.; Colombo, L., Electronics Based on Two-Dimensional Materials. Nat. Nanotechnol. 2014, 9, 768-779.

3. Choi, M. S.; Lee, G.-H.; Yu, Y.-J.; Lee, D.-Y.; Lee, S. H.; Kim, P.; Hone, J.; Yoo, W. J., Controlled Charge Trapping by Molybdenum Disulphide and Graphene in Ultrathin Heterostructured Memory Devices. Nature communications 2013, 4, 1624.

4. Bernardi, M.; Palummo, M.; Grossman, J. C., Extraordinary Sunlight Absorption and One Nanometer Thick Photovoltaics Using Two-Dimensional Monolayer Materials. Nano Lett. 2013, 13, 3664-3670.

5. Surwade, S. P.; Smirnov, S. N.; Vlassiouk, I. V.; Unocic, R. R.; Veith, G. M.; Dai, S.; Mahurin, S. M., Water Desalination Using Nanoporous Single-Layer Graphene. Nat. Nanotechnol. 2015, 10, 459-464.

6. Bonaccorso, F.; Colombo, L.; Yu, G.; Stoller, M.; Tozzini, V.; Ferrari, A. C.; Ruoff, R. S.; Pellegrini, V., Graphene, Related Two-Dimensional Crystals, and Hybrid Systems for Energy Conversion and Storage. Science 2015, 347, 1246501.

7. Liu, Z.; Lau, S. P.; Yan, F., Functionalized Graphene and Other Two-Dimensional Materials for Photovoltaic Devices: Device Design and Processing. Chem. Soc. Rev. 2015, 44, 56385679.

8. Wan, J.; Lacey, S. D.; Dai, J.; Bao, W.; Fuhrer, M. S.; Hu, L., Tuning Two-Dimensional Nanomaterials by Intercalation: Materials, Properties and Applications. Chem. Soc. Rev. 2016, 45, 6742-6765.

9. Amani, M.; Lien, D.-H.; Kiriya, D.; Xiao, J.; Azcatl, A.; Noh, J.; Madhvapathy, S. R.; Addou, R.; Santosh, K.; Dubey, M., Near-unity Photoluminescence Quantum Yield in $\mathrm{MoS}_{2}$. Science 2015, 350, 1065-1068.

10. Naguib, M.; Kurtoglu, M.; Presser, V.; Lu, J.; Niu, J. J.; Heon, M.; Hultman, L.; Gogotsi, Y.; Barsoum, M. W., Two-Dimensional Nanocrystals Produced by Exfoliation of $\mathrm{Ti}_{3} \mathrm{AlC}_{2}$. Adv. Mater. 2011, 23, 4248-4253.

11. Naguib, M.; Mashtalir, O.; Carle, J.; Presser, V.; Lu, J.; Hultman, L.; Gogotsi, Y.; Barsoum, M. W., Two-Dimensional Transition Metal Carbides. ACS Nano 2012, 6, 1322-31.

12. Zhou, J.; Zha, X.; Chen, F. Y.; Ye, Q.; Eklund, P.; Du, S.; Huang, Q., A Two-Dimensional Zirconium Carbide by Selective Etching of $\mathrm{Al}_{3} \mathrm{C}_{3}$ from Nanolaminated $\mathrm{Zr}_{3} \mathrm{Al}_{3} \mathrm{C}_{5}$. Angew. Chem. 2016, 128, 5092-5097. 
13. Barsoum, M. W., MAX Phases: Properties of Machinable Ternary Carbides and Nitrides. John Wiley \& Sons 2013.

14. Halim, J.; Lukatskaya, M. R.; Cook, K. M.; Lu, J.; Smith, C. R.; Näslund, L.-Å.; May, S. J.; Hultman, L.; Gogotsi, Y.; Eklund, P.; Barsoum, M. W., Transparent Conductive TwoDimensional Titanium Carbide Epitaxial Thin Films. Chem. Mater. 2014, 26, 2374-2381.

15. Ghidiu, M.; Lukatskaya, M. R.; Zhao, M.-Q.; Gogotsi, Y.; Barsoum, M. W., Conductive TwoDimensional Titanium Carbide 'Clay' with High Volumetric Capacitance. Nature 2014, 516, 78-81.

16. Ghidiu, M.; Halim, J.; Kota, S.; Bish, D.; Gogotsi, Y.; Barsoum, M. W., Ion-Exchange and Cation Solvation Reactions in $\mathrm{Ti}_{3} \mathrm{C}_{2}$ MXene. Chem. Mater. 2016, 28, 3507-3514.

17. Liu, F.; Zhou, J.; Wang, S.; Wang, B.; Shen, C.; Wang, L.; Hu, Q.; Huang, Q.; Zhou, A., Preparation of High-Purity $\mathrm{V}_{2} \mathrm{C}$ MXene and Electrochemical Properties as Li-Ion Batteries. $J$. Electrochem. Soc. 2017, 164, A709-A713.

18. Halim, J.; Cook, K. M.; Naguib, M.; Eklund, P.; Gogotsi, Y.; Rosen, J.; Barsoum, M. W., XRay Photoelectron Spectroscopy of Select Multi-layered Transition Metal Carbides (MXenes). Appl. Surf. Sci. 2016, 362, 406-417.

19. Ng, V. M. H.; Huang, H.; Zhou, K.; Lee, P. S.; Que, W.; Xu, J. Z.; Kong, L. B., Recent Progress in Layered Transition Metal Carbides and/or Nitrides (MXenes) and their Composites: Synthesis and Applications. Journal of Materials Chemistry A 2017, 5, 3039-3068.

20. Lukatskaya, M. R.; Kota, S.; Lin, Z.; Zhao, M.-Q.; Shpigel, N.; Levi, M. D.; Halim, J.; Taberna, P.-L.; Barsoum, M. W.; Simon, P., Ultra-high-rate Pseudocapacitive Energy Storage in TwoDimensional Transition Metal Carbides. Nature Energy 2017, 2, 17105.

21. Halim, J.; Lukatskaya, M. R.; Cook, K. M.; Lu, J.; Smith, C. R.; Näslund, L.-Å.; May, S. J.; Hultman, L.; Gogotsi, Y.; Eklund, P., Transparent Conductive Two-Dimensional Titanium Carbide Epitaxial Thin Films. Chem. Mater. 2014, 26, 2374-2381.

22. Naguib, M.; Mochalin, V. N.; Barsoum, M. W.; Gogotsi, Y., 25 ${ }^{\text {th }}$ Anniversary Article: MXenes: A New Family of Two-Dimensional Materials. Adv. Mater. 2014, 26, 992-1005.

23. Anasori, B.; Lukatskaya, M. R.; Gogotsi, Y., 2D Metal Carbides and Nitrides (MXenes) for Energy Storage. Nature Reviews Materials 2017, 2, 16098.

24. Eklund, P.; Rosen, J.; Persson, P. O. A.., Layered Ternary $\mathrm{M}_{\mathrm{n}+1} \mathrm{AX}_{\mathrm{n}}$ Phases and their 2D Derivative MXene: An Overview from a Thin-film Perspective. J. Phys. D: Appl. Phys. 2017, 50, 113001.

25. Sun, S.; Liao, C.; Hafez, A. M.; Zhu, H.; Wu, S., Two-Dimensional MXenes for Energy Storage. Chem. Eng. J. (Lausanne) 2017, 15, 27-45.

26. Naguib, M.; Bentzel, G. W.; Shah, J.; Halim, J.; Caspi, E. N.; Lu, J.; Hultman, L.; Barsoum, M. W., New Solid Solution MAX Phases: $\left(\mathrm{Ti}_{0.5}, \mathrm{~V}_{0.5}\right)_{3} \mathrm{AlC}_{2},\left(\mathrm{Nb}_{0.5}, \mathrm{~V}_{0.5}\right)_{2} \mathrm{AlC},\left(\mathrm{Nb}_{0.5}\right.$, $\left.\mathrm{V}_{0.5}\right)_{4} \mathrm{AlC}_{3}$ and $\left(\mathrm{Nb}_{0.8}, \mathrm{Zr}_{0.2}\right)_{2} \mathrm{AlC}$. Materials Research Letters 2014, 2, 233-240.

27. Manoun, B.; Saxena, S.; Hug, G.; Ganguly, A.; Hoffman, E.; Barsoum, M., Synthesis and Compressibility of $\mathrm{Ti}_{3}\left(\mathrm{Al}, \mathrm{Sn}_{0.2}\right) \mathrm{C}_{2}$ and $\mathrm{Ti}_{3} \mathrm{Al}\left(\mathrm{C}_{0.5}, \mathrm{~N}_{0.5}\right)_{2}$. J. Appl. Phys. 2007, 101, 113523.

28. Yang, J.; Naguib, M.; Ghidiu, M.; Pan, L.-M.; Gu, J.; Nanda, J.; Halim, J.; Gogotsi, Y.; Barsoum, M. W., Two-Dimensional Nb-Based $\mathrm{M}_{4} \mathrm{C}_{3}$ Solid Solutions (MXenes). J. Am. Ceram. Soc. 2015, 99, 660-666.

29. Dall'Agnese, Y.; Lukatskaya, M. R.; Cook, K. M.; Taberna, P.-L.; Gogotsi, Y.; Simon, P., High Capacitance of Surface-modified 2D Titanium Carbide in Acidic Electrolyte. Electrochem. Commun. 2014, 48, 118-122. 
30. Persson, I.; Näslund, L.-Å.; Halim, J.; Barsoum, M. W.; Darakchieva, V.; Palisaitis, J.; Rosen, J.; Persson, P. O. Å., On the Organization and Thermal Behavior of Functional Groups on $\mathrm{Ti}_{3} \mathrm{C}_{2}$ MXene Surfaces in Vacuum. 2D Materials 2017, 5, 015002.

31. Tao, Q.; Dahlqvist, M.; Lu, J.; Kota, S.; Meshkian, R.; Halim, J.; Palisaitis, J.; Hultman, L.; Barsoum, M. W.; Persson, P. O., Two-dimensional Mo $1 .{ }_{33} \mathrm{C}$ MXene with Divacancy Ordering Prepared from Parent 3D Laminate with In-plane Chemical Ordering. Nature communications 2017, 8, 14949.

32. Qin, L.; Tao, Q.; El Ghazaly, A.; Fernandez-Rodriguez, J.; Persson, P. O. Å.; Rosen, J.; Zhang, F., High-Performance Ultrathin Flexible Solid-State Supercapacitors Based on Solution Processable Mo1.33C MXene abd PEDOT:PSS. Adv. Funct. Mater. 2017, 28, 1703808.

33. Dahlqvist, M.; Lu, J.; Meshkian, R.; Tao, Q.; Hultman, L.; Rosen, J., Prediction and Synthesis of a Family of Atomic Laminate Phases with Kagomé-like and In-plane Chemical Ordering. Science Advances 2017, 3, 1700642.

34. Lu, J.; Thore, A.; Meshkian, R.; Tao, Q.; Hultman, L.; Rosen, J., Theoretical and Experimental Exploration of a Novel In-plane Chemically-ordered $\left(\mathrm{Cr}_{2 / 3} \mathrm{M}_{1 / 3}\right)_{2} \mathrm{AlC}$ i-MAX Phase with $\mathrm{M}=$ Sc and Y. Cryst. Growth Des. 2017, 17, 5704-5711.

35. Lin, H.; Gao, S.; Dai, C.; Chen, Y.; Shi, J., Two-Dimensional Biodegradable Niobium Carbide (MXene) for Photothermal Tumor Eradication in NIR-I and NIR-II Bio-Windows. J. Am. Chem. Soc. 2017, 139, 16235-16247.

36. Mashtalir, O.; Lukatskaya, M. R.; Zhao, M. Q.; Barsoum, M. W.; Gogotsi, Y., Amine-assisted Delamination of $\mathrm{Nb}_{2} \mathrm{C}$ MXene for Li-Ion Energy Storage Devices. Adv. Mater. 2015, 27, 35013506.

37. Naguib, M.; Halim, J.; Lu, J.; Cook, K. M.; Hultman, L.; Gogotsi, Y.; Barsoum, M. W., New Two-dimensional Niobium and Vanadium Carbides as Promising Materials for Li-ion Batteries. J. Am. Chem. Soc. 2013, 135, 15966-9.

38. Su, T.; Peng, R.; Hood, Z. D.; Naguib, M.; Ivanov, I. N.; Keum, J. K.; Qin, Z.; Guo, Z.; Wu, $\mathrm{Z}$., One-step Synthesis of $\mathrm{Nb}_{2} \mathrm{O}_{5} / \mathrm{C} / \mathrm{Nb}_{2} \mathrm{C}$ (MXene) Composites and their Use as Photocatalysts for Hydrogen Evolution. ChemSusChem 2017, 11, 688-699.

39. Salama, I.; El-Raghy, T.; Barsoum, M. W., Synthesis and Mechanical Properties of Nb${ }_{2} \mathrm{AlC}$ and (Ti,Nb) ${ }_{2}$ AlC. J. Alloys Compd. 2002, 347, 271-278.

40. Cordero, B.; Gómez, V.; Platero-Prats, A. E.; Revés, M.; Echeverría, J.; Cremades, E.; Barragán, F.; Alvarez, S., Covalent Radii Revisited. Dalton Trans. 2008, (21), 2832-2838.

41. Hu, C.; Li, F.; Zhang, J.; Wang, J.; Wang, J.; Zhou, Y., Nb4 AlC $_{3}$ : A New Compound Belonging to the MAX Phases. Scr. Mater. 2007, 57, 893-896.

42. Halim, J.; Chartier, P.; Basyuk, T.; Prikhna, T.; El’ad, N. C.; Barsoum, M. W.; Cabioc’h, T., Structure and Thermal Expansion of $\left(\mathrm{Cr}_{\mathrm{x}}, \mathrm{V}_{1-\mathrm{x}}\right)_{\mathrm{n}+} \mathrm{AlC} \mathrm{n}$ Phases Measured by X-Ray Diffraction. J. Eur. Ceram. Soc. 2017, 37, 15-21.

43. Zhou, Y.; Meng, F.; Zhang, J., New MAX-Phase Compounds in the V-Cr-Al-C System. J. Am. Ceram. Soc. 2008, 91, 1357-1360.

44. Khazaei, M.; Ranjbar, A.; Esfarjani, K.; Bogdanovski, D.; Dronskowski, R.; Yunoki, S., Insights into Exfoliation Possibility of MAX Phases to MXenes. Phys. Chem. Chem. Phys. 2018, 20, 8579-8592.

45. Naguib, M.; Unocic, R. R.; Armstrong, B. L.; Nanda, J., Large-scale Delamination of Multilayers Transition Metal Carbides and Carbonitrides "MXenes". Dalton Trans. 2015, 44, 93538. 
46. Halim, J.; Kota, S.; Lukatskaya, M. R.; Naguib, M.; Zhao, M. Q.; Moon, E. J.; Pitock, J.; Nanda, J.; May, S. J.; Gogotsi, Y., Synthesis and Characterization of 2D Molybdenum Carbide (MXene). Adv. Funct. Mater. 2016, 26, 3118-3127.

47. Ashton, M.; Mathew, K.; Hennig, R. G.; Sinnott, S. B., Predicted Surface Composition and Thermodynamic Stability of MXenes in Solution. The Journal of Physical Chemistry C 2016, 120, 3550-3556.

48. Anasori, B.; Shi, C.; Moon, E. J.; Xie, Y.; Voigt, C. A.; Kent, P. R.; May, S. J.; Billinge, S. J.; Barsoum, M. W.; Gogotsi, Y., Control of Electronic Properties of 2D Carbides (MXenes) by Manipulating their Transition Metal Layers. Nanoscale Horizons 2016, 1, 227-234.

49. Jiang, H.; Johnson, C.; Wang, K., Giant Negative Magnetoresistance of a Degenerate TwoDimensional Electron Gas in the Variable-range-hopping Regime. Phys Rev B 1992, 46, 12830.

50. Zhao, H. L.; Spivak, B. Z.; Gelfand, M. P.; Feng, S., Negative Magnetoresistance in Variablerange-hopping conduction. Phys Rev B 1991, 44 (19), 10760.

51. Gu, H.; Guo, J.; He, Q.; Jiang, Y.; Huang, Y.; Haldolaarachige, N.; Luo, Z.; Young, D. P.; Wei, S.; Guo, Z., Magnetoresistive Polyaniline/multi-walled Carbon Nanotube Nanocomposites with Negative Permittivity. Nanoscale 2014, 6, 181-189.

52. Sybous, A.; El Kaaouachi, A.; Hemine, J.; Narjis, A.; Limouny, L.; Dlimi, S.; Abdia, R.; Biskupski, G., Negative Magnetoresistance Behaviour and Variable Range Hopping Conduction in Insulating NbSi Amorphous Alloys at Very Low Temperature with Magnetic Field. Journal of Modern Physics 2012, 3, 521. 
TOC

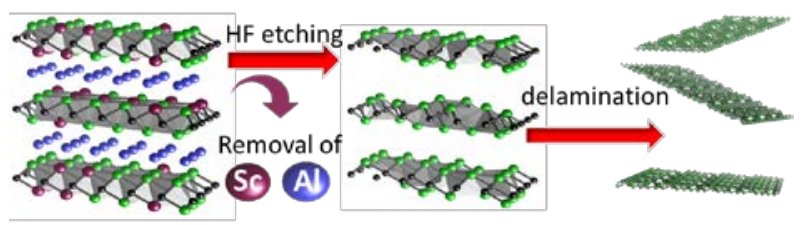




\section{Synthesis of two-dimensional $\mathrm{Nb}_{1.33} \mathrm{C}$ (MXene) with randomly distributed vacancies by etching a $\left(\mathrm{Nb}_{2 / 3} \mathrm{Sc}_{1 / 3}\right)_{2} \mathrm{AlC}$ solid solution}

J. Halim, ${ }^{a}$ J. Palisaitis, ${ }^{a}$ J. Lu, ${ }^{a}$ J. Thörnberg, ${ }^{a}$ E.J. Moon, ${ }^{b}$ M. Precner, ${ }^{c}$ P. Eklund, P. O. A. Persson, ${ }^{a}$ M. W. Barsoum, ${ }^{b}$ and J. Rosen ${ }^{a, *}$

a Thin Film Physics, Department of Physics, Chemistry, and Biology (IFM), Linkoping, Sweden

${ }^{\mathrm{b}}$ Department of Materials Science and Engineering, Drexel University, PA 19104, USA

${ }^{\mathrm{c}}$ Institute of Electrical Engineering, Slovak Academy of Sciences, 84104 Bratislava, Slovak Republic

Corresponding author:*johanna.rosen@liu.se 


\section{Materials and methods}

\subsection{MAX and MXene synthesis}

Synthesis of $\left(\mathrm{Nb}_{2 / 3} \mathrm{Sc}_{1 / 3}\right)_{2} \mathrm{AlC}$ : Powders of $\left(\mathrm{Nb}_{2 / 3} \mathrm{Sc}_{1 / 3}\right)_{2} \mathrm{AlC}$ were synthesized by a solid state reaction of elemental powders. Powders of $\mathrm{Nb}$ (99.8\%, 325 mesh, Alfa Aesar, Kandel, Germany), Sc (99.99\%, Standford Advanced Material, USA), Al (99.5\%, 325 mesh, Alfa Aesar, Kandel, Germany) and C (99.9995\%, 200 mesh, Alfa Aesar, Karlsruhe, Germany) were placed in an agate mortar in a 4/3:2/3:1:1 molar ratio and manually mixed. After mixing they was poured in a Teflon jar and hand shaken for $5 \mathrm{~min}$. The mixture was heated at a rate of 5 ${ }^{\circ} \mathrm{C} / \mathrm{min}$ to $1400{ }^{\circ} \mathrm{C}$ in an alumina crucible under $5 \mathrm{sccm}$ Ar flow and held at $1400{ }^{\circ} \mathrm{C}$ for $2 \mathrm{~h}$. After furnace cooling, the lightly sintered sample was crushed, using the agate mortar and pestle and sieved through a 450 mesh sieve.

Synthesis of $\mathrm{Nb}_{2} \mathrm{AlC}$ : Powders of $\mathrm{Nb}_{2} \mathrm{AlC}$ were synthesized by a solid state reaction of elemental powders as detailed in Ref. ${ }^{1}$ In short, powders of $\mathrm{Nb}$ (99.8\%, 325 mesh, Alfa Aesar, Kandel, Germany), Al (99.5\%, 325 mesh, Alfa Aesar, Kandel, Germany) and C (99.9995\%, 200 mesh, Alfa Aesar, Karlsruhe, Germany) were mixed as above and heated at a rate of $5{ }^{\circ} \mathrm{C} / \mathrm{min}$ to $1600{ }^{\circ} \mathrm{C}$ in an alumina crucible under $5 \mathrm{sccm}$ Ar flow and held at $1600{ }^{\circ} \mathrm{C}$ for $2 \mathrm{~h}$. After furnace cooling, the lightly sintered sample was crushed, using the agate mortar and pestle and sieved through a 450 mesh sieve.

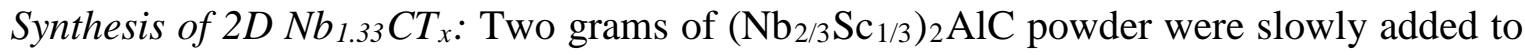
a Teflon bottle containing $40 \mathrm{ml}$ of $48 \%$ aqueous HF (Honeywell Fluka, Sweden). The bottle containing the mixture was placed on a stir plate at room temperature and the mixture was stirred using a Teflon coated magnet for $30 \mathrm{~h}$. The resulting suspension was washed with DI water for several cycles till the a $\mathrm{pH}$ of $\approx 6$ was reached. In each washing cycle $40 \mathrm{ml}$ of DI water were added to the mixture in a centrifuge tube and the tube was hand-shaken for $1 \mathrm{~min}$ before centrifuging at $5000 \mathrm{rpm}$ for $1 \mathrm{~min}$. The settled powder was removed from the centrifuge tube and filtered through a nanoporous polypropylene membrane (3501 Coated PP, $0.064 \mu \mathrm{m}$ pore size, Celgard, LLC, USA) for further investigation.

One gram of the filtered powder was added to a $5 \mathrm{ml}$ of an aqueous solution of 54-56 wt.\% TBAOH, $\left(\mathrm{C}_{4} \mathrm{H}_{9}\right)_{4} \mathrm{NOH}$, (Sigma Aldrich, Sweden). The mixture was hand-shaken for 5 min then washed 3 times by $40 \mathrm{ml}$ DI each time; the resulting sediment was used for further characterization and delamination.

To obtain a delaminated $\mathrm{Nb}_{1.33} \mathrm{CT}_{\mathrm{x}}$ colloidal suspension and free-standing films, the TBAOH intercalated powder was mixed with water ( $1 \mathrm{~g} \mathrm{Nb}_{1.33} \mathrm{CT}_{\mathrm{x}}$ per $50 \mathrm{ml}$ of DI water) and hand-shaken for $5 \mathrm{~min}$. Then the mixture was centrifuged for $1 \mathrm{~h}$ at $5000 \mathrm{rpm}$ and the supernatant - which was comprised of, presumably, single or few delaminated $\mathrm{Nb}_{1.33} \mathrm{CT}_{\mathrm{x}}$ flakes at a concentration of $1 \mathrm{mg} / \mathrm{ml}$ - was collected. The suspension was then vacuum-filtered onto a nanoporous polypropylene membrane (3501 Coated PP, $0.064 \mu \mathrm{m}$ pore size, Celgard, LLC, USA) in air. The delaminated $d-\mathrm{Nb}_{1.33} \mathrm{CT}_{\mathrm{x}}$ "paper" was easily separated from the membrane to obtain free-standing, flexible $\mathrm{Nb}_{1.33} \mathrm{CT}_{\mathrm{x}}$ films.

Synthesis of $2 \mathrm{D} \mathrm{Nb}_{2} \mathrm{CT}_{x}$ : Two grams of $\mathrm{Nb}_{2} \mathrm{AlC}$ powder were slowly immersed in a Teflon bottle containing $20 \mathrm{ml}$ of $48 \%$ aqueous HF. The bottle containing the mixture was placed on a stir plate at room temperature and the mixture was stirred using a Teflon coated magnet for 100 hr. The resulting suspension was washed with DI water for several cycles till the mixture reached a $\mathrm{pH}$ of $\approx 6$. In each washing cycle $40 \mathrm{ml}$ of DI water were added to the mixture in a centrifuge tube and the tube was hand-shaken for $1 \mathrm{~min}$ before centrifuging at $5000 \mathrm{rpm}$ for 1 
min. The settled powder was removed from the centrifuge tube and filtered through a nanoporous polypropylene membrane for further investigation.

One gram of the filtered powdered was added to a $5 \mathrm{ml}$ of an aqueous solution of 54-56 wt.\% TBAOH, $\left(\mathrm{C}_{4} \mathrm{H}_{9}\right)_{4} \mathrm{NOH}$. The mixture was hand-shaken for 5 min then washed 3 times by $40 \mathrm{ml}$ DI each time and the sediment was used for further characterization and delamination.

To obtain a $\mathrm{Nb}_{2} \mathrm{CT}_{\mathrm{x}}$ colloidal suspension and free-standing film, the TBAOH intercalated powder was mixed with water $\left(1 \mathrm{~g} \mathrm{Nb}_{2} \mathrm{CT}_{\mathrm{x}}\right.$ per $50 \mathrm{ml}$ of DI water) and sonicated using an ultrasonication bath for $1 \mathrm{~h}$. Sonication was performed while the mixture was bubbled with $\mathrm{N}_{2}$ gas. The mixture was then centrifuged for $1 \mathrm{~h}$ at $5000 \mathrm{rpm}$ and the supernatant - which was comprised of, presumably, single or few delaminated $\mathrm{Nb}_{1.33} \mathrm{CT}_{\mathrm{x}}$ flakes at a concentration of 0.5 $\mathrm{mg} / \mathrm{ml}$ - was collected. The suspension was then vacuum-filtered onto nanoporous polypropylene membrane in air. Unfortunately, the delaminated $d-\mathrm{Nb}_{2} \mathrm{CT}_{\mathrm{x}}$ "paper" was stuck to the membrane and attempts to separate the two from each other resulted in the breakdown of the film into small brittle pieces.

\subsection{Materials characterization}

The microstructures and morphologies of the MAX and MXene samples were characterized by Scanning Transmission Electron Microscope (STEM) combined with high angle annular dark field imagining (STEM-HAADF) in a double-corrected Linköping FEI Titan ${ }^{3}$ 60-300, operated at both $300 \mathrm{kV}$ and $60 \mathrm{kV}$ and Transmission Electron Microscopy (TEM) FEI Tecnai T20 operated at $200 \mathrm{kV}$ accompanied with Selected Area Electron Diffraction (SAED). The MAX phase sample was prepared by embedding the ground-mixed powder in a Cu grid with a carbon film. For the delaminated MXene flakes, a few from a water suspension were drop cast on to the $\mathrm{Cu}$ grid with carbon film.

Scanning Electron Microscopy (SEM) imaging was performed using a SEM LEO 1550 Gemini operated with an acceleration voltage between 5 and $15 \mathrm{keV}$ equipped with an Oxford INCA Energy E2H X-ray Energy Dispersive Spectrometer (EDS) system with Silicon Drifted detector.

X-ray diffraction (XRD) was carried out on a PANalytical X'Pert powder diffraction, with Cu source $\left(\lambda_{\mathrm{K} \alpha} \approx 1.54 \AA\right)$. A graded Bragg-Brentano with a $1 / 4^{\circ}$ divergent and $1 / 2^{\circ}$ anti-scatter slits, and a $5 \mathrm{~mm}$ anti-scatter slit together with a Soller slit (with an opening of 0.04 radian), in the incident and the diffracted beam sides were used, respectively.

The XRD pattern of the $\left(\mathrm{Nb}_{2 / 3} \mathrm{Sc}_{1 / 3}\right)_{2} \mathrm{AlC}$ powder was analysed by the Rietveld refinement method, using the FULLPROF code. $^{2-3}$ Refined parameters were scale factors from which relative phase fractions were evaluated, $X$ and $Y$ profile parameters for peak width, lattice parameters (LPs) and atomic positions for all phases in addition to the occupancies of $\mathrm{Nb}$ and $\mathrm{Sc}$ atoms in the $\left(\mathrm{Nb}_{2 / 3} \mathrm{Sc}_{1 / 3}\right)_{2} \mathrm{AlC}$ and $\mathrm{Nb}$ and $\mathrm{Sc}$ atoms in $\left(\mathrm{Nb}_{2 / 3} \mathrm{Sc}_{1 / 3}\right)_{3} \mathrm{AlC}_{2}$ occupying the atomic position $(0.333,0.667,0.122)$. The background was refined via linear extrapolation of a manually selected background.

X-ray photoelectron spectroscopy (XPS) measurements were performed on a free-standing $d-\mathrm{Nb}_{1.33} \mathrm{CT}_{\mathrm{x}}$ film and a $d-\mathrm{Nb}_{2} \mathrm{CT}_{\mathrm{x}}$ film stuck on the filter membrane using a surface analysis system (Kratos AXIS Ultra ${ }^{\text {DLD }}$, Manchester, U.K.) with monochromatic Al-Ka (1486.6 eV) radiation. Each sample was mounted on a double-sided tape and grounded to the sample stage with copper contacts. The X-ray beam irradiated the sample surface at an angle of $45^{\circ}$, with respect to the surface and provided an X-ray spot of $\approx 300 \times 800 \mu \mathrm{m}$. Charge neutralization was performed using a co-axial, low energy $(\sim 0.1 \mathrm{eV})$ electron flood source to avoid shifts in the recorded binding energy (BE). XPS spectra were recorded for $\mathrm{F} 1 \mathrm{~s}, \mathrm{O} 1 \mathrm{~s}, \mathrm{C} 1 \mathrm{~s}, \mathrm{Al} 2 \mathrm{p}$, and $\mathrm{Nb}$ $3 \mathrm{~d}$ and Sc 2p. The analyser pass energy used for all the regions was $20 \mathrm{eV}$ with a step size of $0.1 \mathrm{eV}$. The BE scale of all XPS spectra was referenced to the Fermi-edge $\left(E_{F}\right)$, which was set 
to a BE of zero eV. The peak fitting was carried out using CasaXPS Version 2.3.16 RP 1.6 in the same manner as in references ${ }^{4-7}$. The global elemental percentage was quantified as in references $^{4-7}$.

The temperature-dependent in-plane resistivity measurements were performed in a Physical Property Measurement System (PPMS) controlled by the Model 6000 for temperatures from 1.9 to $400 \mathrm{~K}$ and external magnetic field up to $14 \mathrm{~T}$.

\section{Results for the Rietveld refinement of the XRD pattern of $\left(\mathrm{Nb}_{2 / 3} \mathrm{Sc}_{1 / 3}\right)_{2} \mathrm{AlC}$ powder}

Table S1. Rietveld refinement of $\left(\mathrm{Nb}_{2 / 3} \mathrm{Sc}_{1 / 3}\right)_{2} \mathrm{AlC},\left(\mathrm{Nb}_{2 / 3} \mathrm{Sc}_{1 / 3}\right)_{3} \mathrm{AlC}_{2}$ and $\left(\mathrm{Nb}_{2 / 3} \mathrm{Sc}_{1 / 3}\right)_{4} \mathrm{AlC}_{3}$ phases of XRD pattern shown in Fig. 1e. The mass fractions of the different phases were: $\left(\mathrm{Nb}_{2 / 3} \mathrm{Sc}_{1 / 3}\right)_{2} \mathrm{AlC}$ (68(2) wt.\%), $\mathrm{NbAl}_{3}$ (10.1(4) wt.\%), $\mathrm{NbC}$ (17.4(4) wt.\%), $\left(\mathrm{Nb}_{2 / 3} \mathrm{Sc}_{1 / 3}\right)_{3} \mathrm{AlC}_{2}$ (2.5(3) wt.\%) and $\left(\mathrm{Nb}_{2 / 3} \mathrm{Sc}_{1 / 3}\right)_{4} \mathrm{AlC}_{3}(2.0(2) \mathrm{wt} . \%)$. The total $\chi^{2}$ value was 8.78 .

\begin{tabular}{|c|c|c|c|}
\hline & $\left(\mathrm{Nb}_{2 / 3} \mathrm{Sc}_{1 / 3}\right)_{2} \mathrm{AlC}$ & $\left(\mathrm{Nb}_{2 / 3} \mathrm{Sc}_{1 / 3}\right)_{3} \mathrm{AlC}_{2}$ & $\left(\mathrm{Nb}_{2 / 3} \mathrm{Sc}_{1 / 3}\right)_{4} \mathrm{AlC}_{3}$ \\
\hline Space group & $P$ 63/mmc & $P$ 63/mmc & $P$ 63/mmc \\
\hline $\begin{array}{c}\text { Lattice } \\
\text { constants }(\AA)\end{array}$ & $\begin{array}{l}a: 3.12915(5) \\
c: 13.9736(3)\end{array}$ & $\begin{array}{l}a: 3.0213(3) \\
c: 19.116(4)\end{array}$ & $\begin{array}{l}a: 3.1855(5) \\
c: 23.878(6)\end{array}$ \\
\hline $\mathrm{Nb}$ and $\mathrm{Sc}$ & $\begin{array}{c}4 f(0.333330 .66667 \\
0.0903(1)) \\
\text { Occupancy of } N b=2.769(7) \\
\text { and } S c=1.231(7)\end{array}$ & $\begin{array}{c}4 f(0.33333 \quad 0.66667 \\
0.122(1)) \\
\text { Occupancy of } N b=2.63(3) \\
\text { and } S c=1.37(3) \\
2 a(0.000 \quad 0.000 \quad 0.000) \\
\text { Occupancy of } N b=1.333 \\
\text { and } S c=0.666 \\
\end{array}$ & 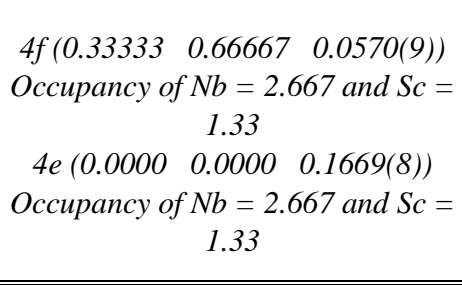 \\
\hline $\mathrm{Al}$ & $2 d\left(\begin{array}{lll}0.667 & 0.333 & 0.250\end{array}\right)$ & $2 b\left(\begin{array}{lll}0.667 & 0.333 & 0.250\end{array}\right)$ & $2 c\left(\begin{array}{lll}0.667 & 0.333 & 0.25\end{array}\right)$ \\
\hline $\mathrm{C}$ & $2 a\left(\begin{array}{lll}0.000 & 0.000 & 0.000\end{array}\right)$ & $4 f\left(\begin{array}{lll}0.000 & 0.000 & 0.503\end{array}\right)$ & $\begin{array}{c}4 f\left(\begin{array}{lll}0.667 & 0.333 & 0.11640\end{array}\right) \\
2 a\left(\begin{array}{lll}0.000 & 0.000 & 0.000\end{array}\right)\end{array}$ \\
\hline
\end{tabular}

\section{EDS for $\left(\mathrm{Nb}_{2 / 3} \mathrm{Sc}_{1 / 3}\right) \mathrm{AlC}_{2}$}

Table S2. Elemental composition of $\left(\mathrm{Nb}_{2 / 3} \mathrm{Sc}_{1 / 3}\right) \mathrm{AlC}_{2} \mathrm{MAX}$ obtained by EDS, excluding C. The elemental composition was taken by averaging the elemental composition of 10 particles.

\begin{tabular}{cccc} 
Element & $\mathrm{Nb}$ & $\mathrm{Sc}$ & $\mathrm{Al}$ \\
\hline Atomic \% & $40.5 \pm 1.0$ & $27.0 \pm 0.7$ & $32.5 \pm 0.8$ \\
\hline
\end{tabular}


4. Electron Energy Loss Spectra for $\mathbf{N b}_{1.33} \mathrm{CT}_{\mathrm{x}}$ single flake

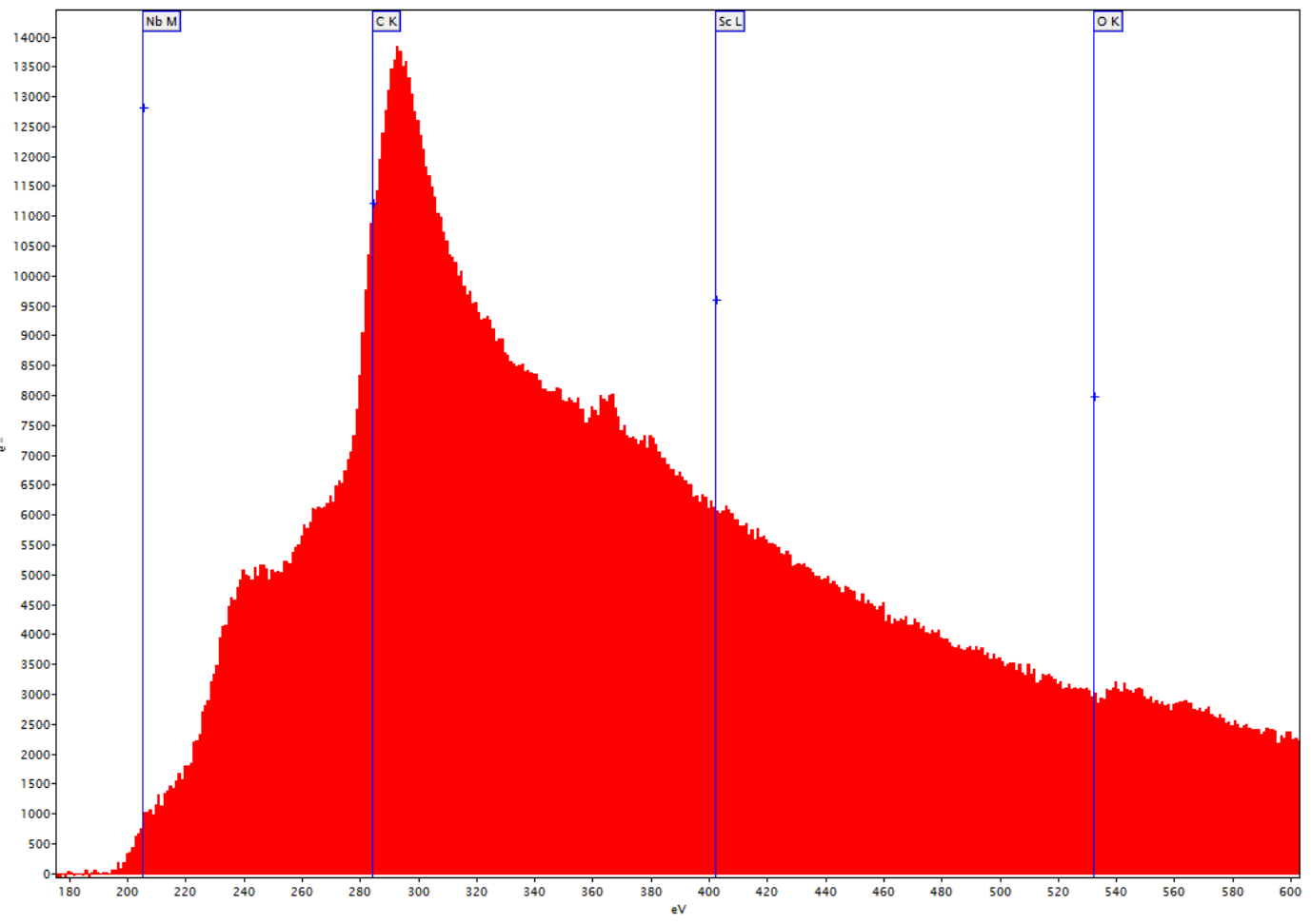

Figure S1. Typical EELS spectra showing Nb-M, C-K and O-K edges from a $\mathrm{Nb}_{1.33} \mathrm{CT}_{\mathrm{x}}$ single flake.

5. Statistical image analysis of vacancy clusters in a single $\mathbf{N b}_{1.33} \mathrm{CT}_{\mathrm{x}}$ flake

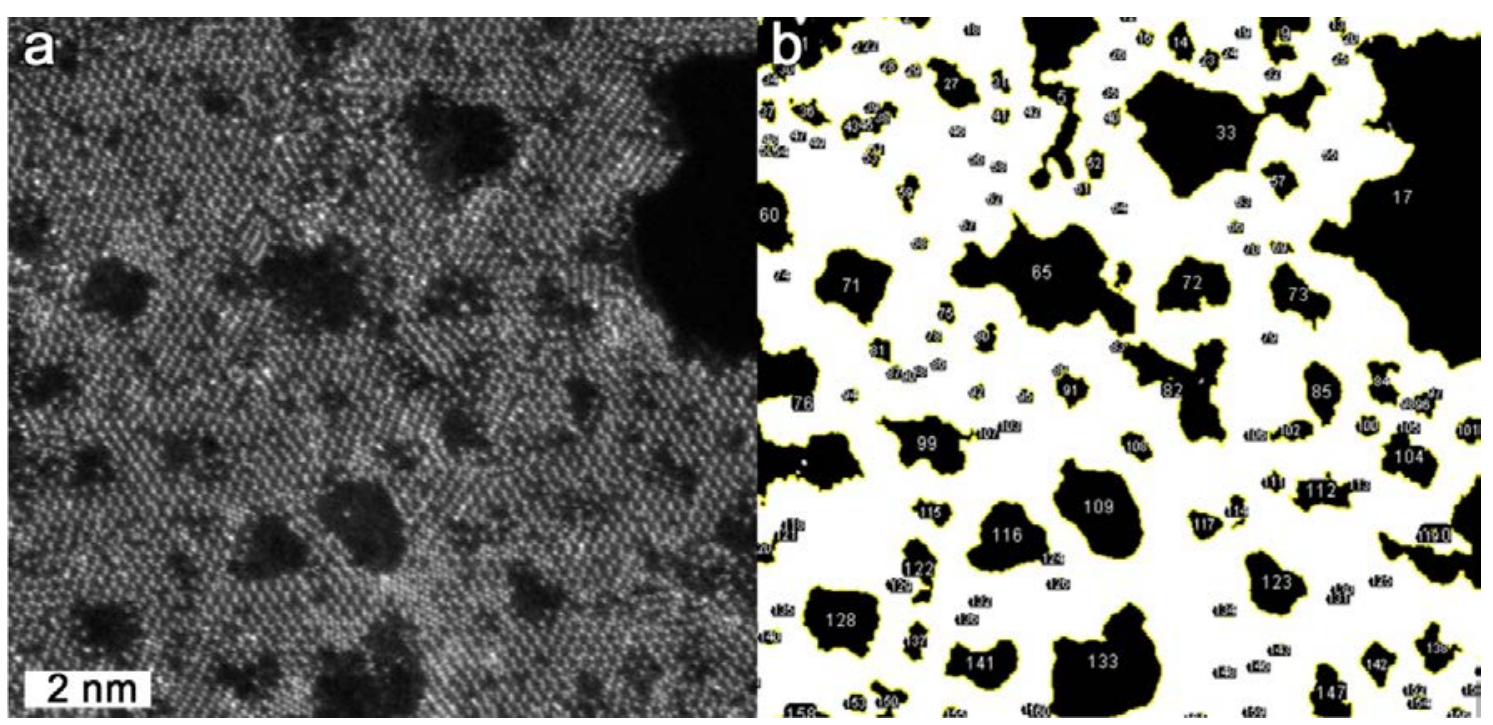

Figure S2. Statistical analysis performed by ImageJ on (a) HRSTEM image obtained from a single $\mathrm{Nb}_{1.33} \mathrm{CT}_{\mathrm{x}}$ flake. (b) mapped out defects (as black areas) which are covering $30 \%$ of the overall image area. 


\section{XPS analysis of $d-\mathrm{Nb}_{1.33} \mathrm{CT}_{\mathrm{x}}$ and $d-\mathrm{Nb}_{2} \mathrm{CT}_{\mathrm{x}}$ free-standing films}

Table S3. Summary of elemental global atomic percentages for MXenes

\begin{tabular}{|ccccccc|}
\hline & $\mathrm{Nb}$ & $\mathrm{C}$ & $\mathrm{O}$ & $\mathrm{F}$ & $\mathrm{Al}$ & $\mathrm{N}$ \\
\hline $\mathrm{Nb}_{1.33} \mathrm{CT}_{\mathrm{x}}$ & $12.9 \pm 0.04$ & $58.7 \pm 0.7$ & $26.8 \pm 0.3$ & $1.7 \pm 0.1$ & $<0.1$ & \\
\hline $\mathrm{Nb}_{2} \mathrm{CT}_{\mathrm{x}}$ & $19.3 \pm 0.08$ & $51.1 \pm 1.0$ & $26.8 \pm 0.3$ & $0.8 \pm 0.1$ & $<0.1$ & $2.0 \pm 0.3$ \\
\hline
\end{tabular}
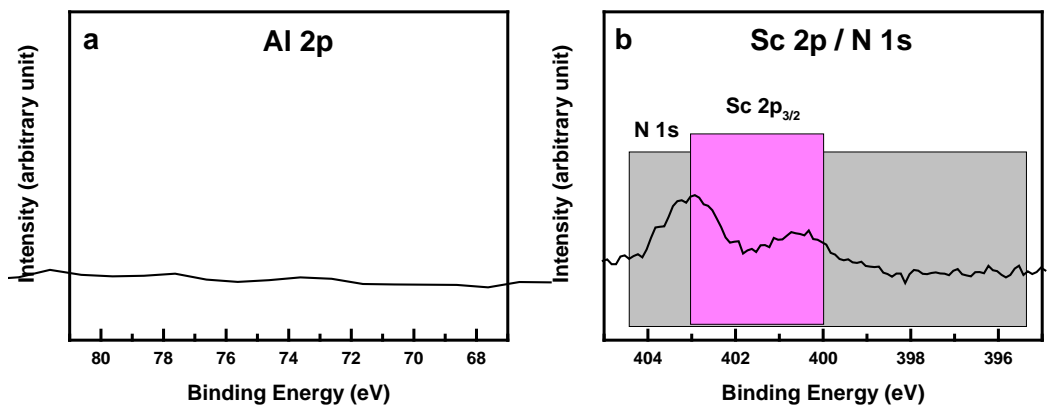

Figure S3. XPS spectra of $d-\mathrm{Nb}_{1.33} \mathrm{CT}_{\mathrm{x}}$ “paper” for (a) $\mathrm{Al} 2 \mathrm{p}$, and (b) $\mathrm{N} 1 \mathrm{~s}$.

Table S4. XPS peak fitting results for a $d-\mathrm{Nb}_{1.33} \mathrm{CT}_{\mathrm{x}}$ free-standing film. The numbers in parenthesis in column 2 for the $\mathrm{Nb} 3 \mathrm{~d}$ region are peak locations of $\mathrm{Nb} 3 \mathrm{~d}_{3 / 2}$; their respective FWHMs are listed in column 3 in parenthesis.

\begin{tabular}{|c|c|c|c|c|c|}
\hline Region & $\mathrm{BE}[\mathrm{eV}]^{\mathrm{a}}$ & FWHM $[\mathrm{eV}]^{\mathrm{a}}$ & Fraction & Assigned to & Reference \\
\hline \multirow{3}{*}{$\mathrm{Nb} 3 \mathrm{~d}_{5 / 2}\left(3 \mathrm{~d}_{3 / 2}\right)$} & $205.0(207.8)$ & $1.6(1.7)$ & 0.48 & C-Nb-Tx & {$\left[{ }^{8-9}\right]$} \\
\hline & $207.6(210.4)$ & $1.3(1.3)$ & 0.49 & $\mathrm{Nb}_{2} \mathrm{O}_{5}$ & {$[8,10-11]$} \\
\hline & 209.7 (212.5) & $1.2(1.8)$ & 0.03 & $\mathrm{NbF}_{5}$ & {$\left[{ }^{12}\right]$} \\
\hline \multirow{5}{*}{ C 1s } & 282.5 & 0.8 & 0.08 & C-Nb-T $T_{x}$ & {$\left[{ }^{13}\right]$} \\
\hline & 285.1 & 1.4 & 0.08 & $\mathrm{C}-\mathrm{C}$ & {$\left[{ }^{14}\right]$} \\
\hline & 285.7 & 1.3 & 0.46 & $\mathrm{CH}_{\mathrm{x}}$ & {$\left[{ }^{14}\right]$} \\
\hline & 286.7 & 1.8 & 0.36 & $\mathrm{C}-\mathrm{O}$ & {$\left[{ }^{14}\right]$} \\
\hline & 288.8 & 1.2 & 0.02 & $\mathrm{COO}$ & {$\left[{ }^{14}\right]$} \\
\hline \multirow{4}{*}{ O 1s } & 530.6 & 1.3 & 0.56 & $\mathrm{Nb}_{2} \mathrm{O}_{5}$ & {$\left[{ }^{15-18}\right]$} \\
\hline & 531.4 & 1.7 & 0.28 & C-Nb-O ${ }_{x}$ & {$\left[{ }^{18}\right]$} \\
\hline & 532.7 & 1.5 & 0.11 & $\mathrm{C}-\mathrm{Nb}-(\mathrm{OH})_{\mathrm{x}}$ & {$\left[{ }^{18}\right]$} \\
\hline & 533.7 & 1.3 & 0.05 & $\mathrm{H}_{2} \mathrm{O}_{\text {ads }}$ & {$\left[{ }^{18}\right]$} \\
\hline \multirow{2}{*}{ F 1s } & 684.8 & 1.5 & 0.59 & C-Nb-Fx & \\
\hline & 686.2 & 2.1 & 0.41 & $\mathrm{NbF}_{3}$ and/or $\mathrm{ScF}_{3}$ & {$[12,19]$} \\
\hline
\end{tabular}



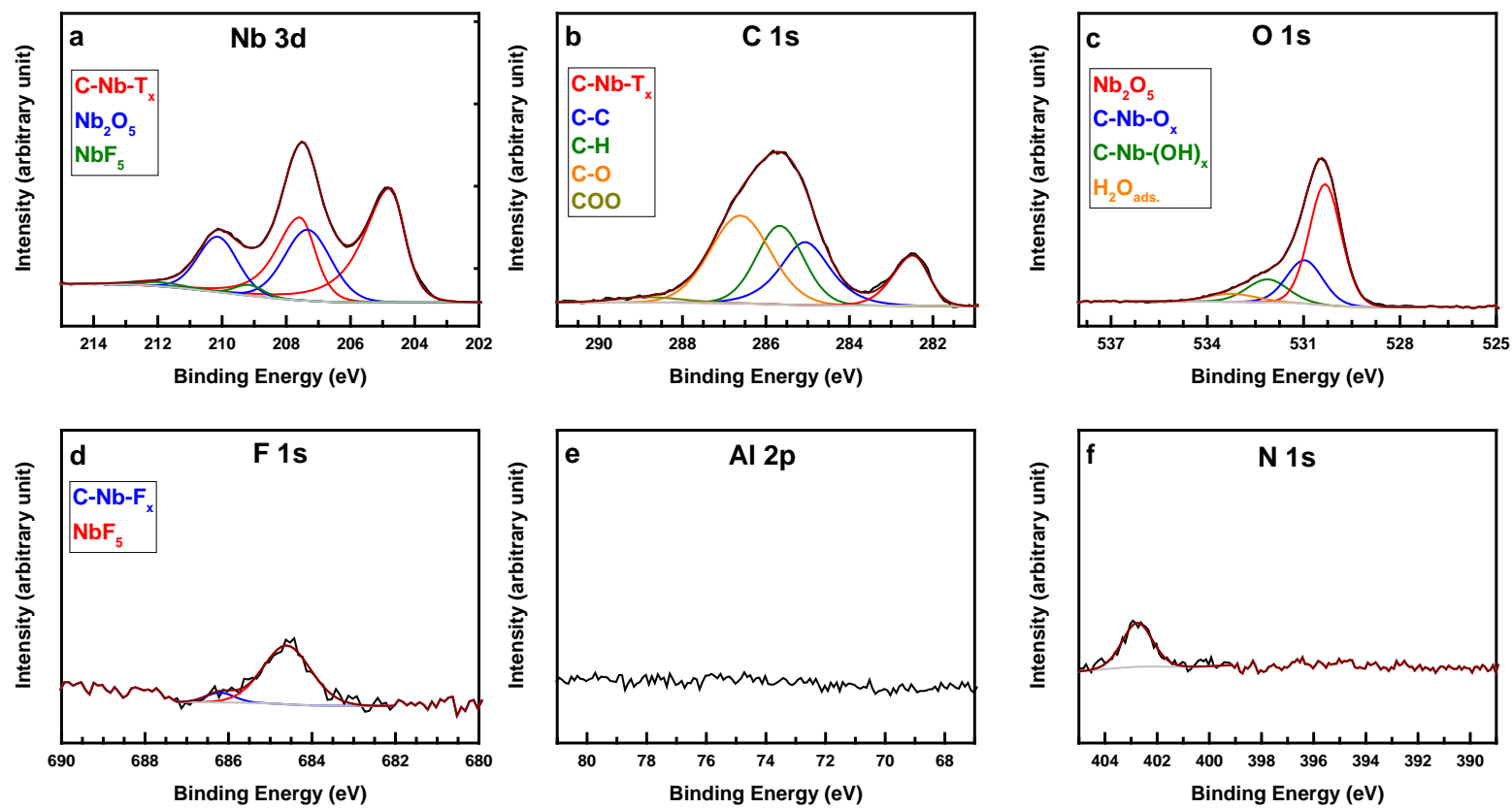

Figure S4. XPS spectra of $d-\mathrm{Nb}_{2} \mathrm{CT}_{\mathrm{x}}$ free-standing film for, (a) $\mathrm{Nb} 3 \mathrm{~d}$, (b) C 1s, (c) O 1s, (d) $\mathrm{F} 1 \mathrm{~s}$, (e) $\mathrm{Al}$ 2p, and, (f) N 1s. Color coded fitting peaks represent various assigned species (See Table S5).

Table S5. XPS peak fitting results for delaminated $\mathrm{Nb}_{2} \mathrm{CT}_{\mathrm{x}}$ free-standing film. The numbers in parenthesis in column 2 for the $\mathrm{Nb} 3 \mathrm{~d}$ region are peak locations of $\mathrm{Nb} 3 \mathrm{~d}_{3 / 2}$; their respective FWHMs are listed in column 3 in parenthesis.

\begin{tabular}{|c|c|c|c|c|c|}
\hline Region & $\mathrm{BE}[\mathrm{eV}]^{\mathrm{a}}$ & FWHM [eV] & Fraction & Assigned to & Reference \\
\hline \multirow{3}{*}{$\mathrm{Nb} 3 \mathrm{~d}_{5 / 2}\left(3 \mathrm{~d}_{3 / 2}\right)$} & 204.8 (207.6) & $1.1(1.2)$ & 0.60 & C-Nb-Tx & {$\left[{ }^{8-9}\right]$} \\
\hline & 207.3 (210.1) & $1.7(1.5)$ & 0.37 & $\mathrm{Nb}_{2} \mathrm{O}_{5}$ & {$\left[{ }^{8,10-11}\right]$} \\
\hline & $209.2(212.0)$ & $1.0(1.9)$ & 0.03 & $\mathrm{NbF}_{5}$ & {$\left[{ }^{12}\right]$} \\
\hline \multirow{5}{*}{ C 1s } & 282.5 & 0.9 & 0.13 & C-Nb-T $T_{x}$ & {$\left[{ }^{13}\right]$} \\
\hline & 285.1 & 1.4 & 0.23 & C-C & {$\left[{ }^{14}\right]$} \\
\hline & 285.7 & 1.3 & 0.25 & $\mathrm{CH}_{\mathrm{x}}$ & {$\left[{ }^{14}\right]$} \\
\hline & 286.6 & 1.7 & 0.36 & $\mathrm{C}-\mathrm{O}$ & {$\left[{ }^{14}\right]$} \\
\hline & 288.8 & 1.9 & 0.03 & $\mathrm{COO}$ & {$\left[{ }^{14}\right]$} \\
\hline \multirow{4}{*}{$\mathrm{O} 1 \mathrm{~s}$} & 530.3 & 1.2 & 0.57 & $\mathrm{Nb}_{2} \mathrm{O}_{5}$ & {$\left[{ }^{15-18}\right]$} \\
\hline & 531.0 & 1.3 & 0.23 & C-Nb-Ox & {$\left[{ }^{18}\right]$} \\
\hline & 532.1 & 1.5 & 0.14 & C-Nb- $(\mathrm{OH})_{\mathrm{x}}$ & {$\left[{ }^{18}\right]$} \\
\hline & 533.3 & 1.8 & 0.06 & $\mathrm{H}_{2} \mathrm{O}_{\text {ads }}$ & {$\left[{ }^{18}\right]$} \\
\hline \multirow{2}{*}{ F 1s } & 684.6 & 1.4 & 0.91 & C-Nb-Fx & \\
\hline & 686.2 & 1.0 & 0.09 & $\mathrm{NbF}_{5}$ & {$\left[{ }^{12,19}\right]$} \\
\hline $\mathrm{N}$ 1s & 402.8 & 1.4 & 1.0 & $\mathrm{TBA}^{+}$ & 20 \\
\hline
\end{tabular}




\section{Transport analysis of $d-\mathrm{Nb}_{1.33} \mathrm{CT}_{\mathrm{x}}$ free-standing films}
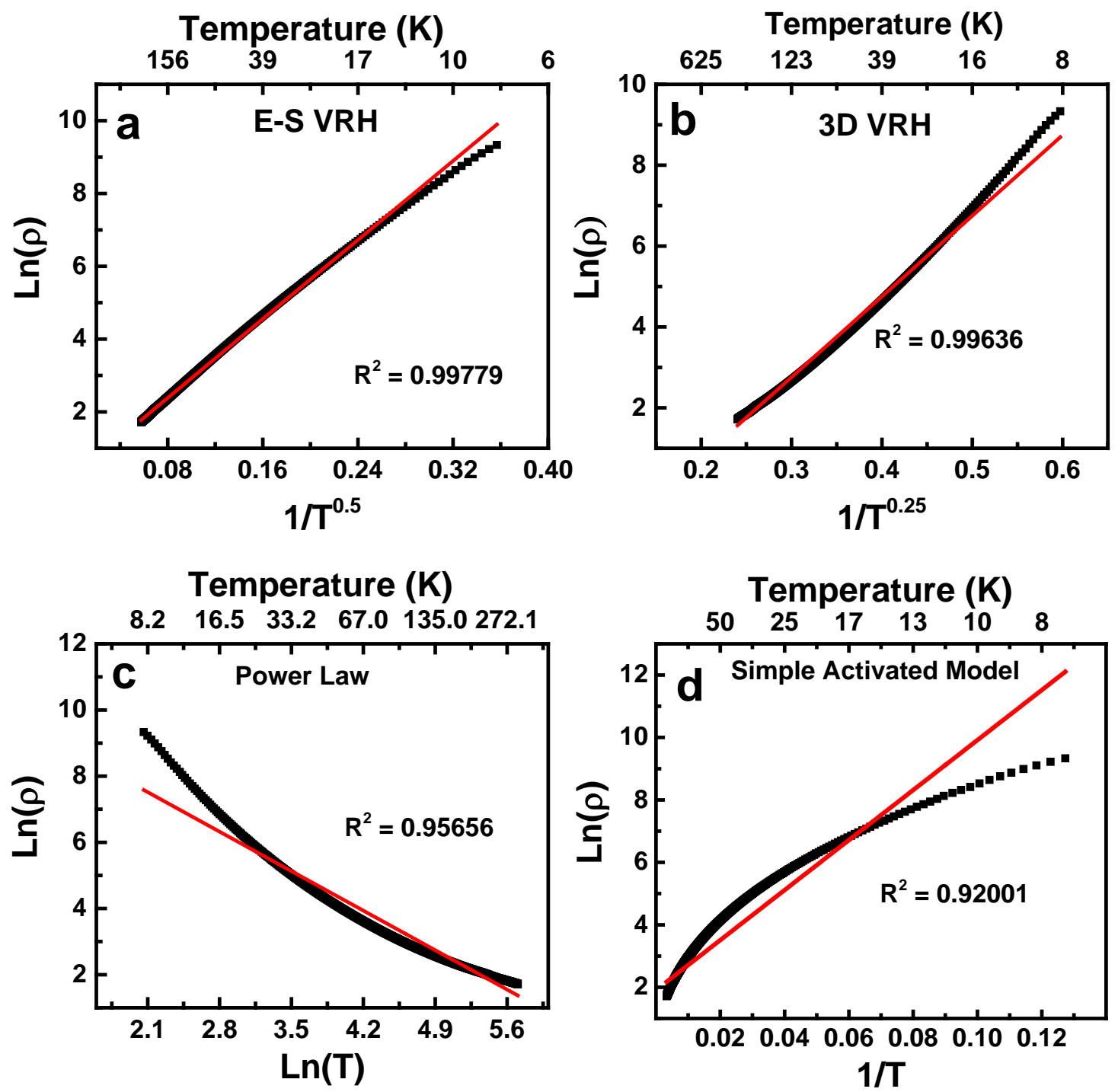

Figure S5. Fitting of the resistivity of a $22 \mu \mathrm{m}$ thick $d-\mathrm{Nb}_{1.33} \mathrm{CT}_{\mathrm{x}}$ film in the 7 to $300 \mathrm{~K}$ temperature range assuming: (a) E-S variable range hopping, (b) 3D variable range hopping (3D VRH), (c) power law and, (d) simple activated models.

\section{References}

1. Naguib, M.; Halim, J.; Lu, J.; Cook, K. M.; Hultman, L.; Gogotsi, Y.; Barsoum, M. W., New Two-Dimensional Niobium and Vanadium Carbides as Promising Materials for Li-ion Batteries. J. Am. Chem. Soc. 2013, 135, 15966-9.

2. Rietveld, H. M., A Profile Refinement Method for Nuclear and Magnetic Structures. J. Appl. Crystallogr. 1969, 2, 65-71.

3. Rodríguez-Carvajal, J., Recent Advances in Magnetic Structure Determination by Neutron Powder Diffraction. Physica B: Condensed Matter 1993, 192, 55-69.

4. Halim, J.; Kota, S.; Lukatskaya, M. R.; Naguib, M.; Zhao, M. Q.; Moon, E. J.; Pitock, J.; Nanda, J.; May, S. J.; Gogotsi, Y., Synthesis and characterization of 2D molybdenum carbide (MXene). Adv. Funct. Mater. 2016, 26, 3118-3127. 
5. Halim, J.; Cook, K. M.; Naguib, M.; Eklund, P.; Gogotsi, Y.; Rosen, J.; Barsoum, M. W., XRay Photoelectron Spectroscopy of Select Multi-Layered Transition Metal Carbides (MXenes). Appl. Surf. Sci. 2016, 362, 406-417.

6. Halim, J., An X-Ray Photoelectron Spectroscopy Study of Multilayered Transition Metal Carbides (MXenes). Drexel University, 2016.

7. Ghidiu, M.; Halim, J.; Kota, S.; Bish, D.; Gogotsi, Y.; Barsoum, M. W., Ion-Exchange and Cation Solvation Reactions in $\mathrm{Ti}_{3} \mathrm{C}_{2}$ MXene. Chem. Mater. 2016, 28, 3507-3514.

8. Halbritter, J.; Darlinski, A., Angle Resolved XPS Studies of Oxides at Nb-, NbN-, NbC- and $\mathrm{Nb}_{3} \mathrm{Sn}$ - Surfaces. IEEE Trans. Magn. 1987, 23, 1381-1384.

9. Marques, M. T.; Ferraria, A. M.; Correia, J. B.; Rego, A. M. B. d.; Vilar, R., XRD, XPS and SEM Characterisation of $\mathrm{Cu}-\mathrm{NbC}$ Nanocomposite Produced by Mechanical Alloying. Mater. Chem. Phys. 2008, 109, 174-180.

10. Miller, C. F.; Simmons, G. W.; Wei, R. P., High Temperature Oxidation of Nb, NbC and $\mathrm{Ni}_{3} \mathrm{Nb}$ and Oxygen Enhanced Crack Growth. Scr. Mater. 2000, 42, 227-232.

11. Weibin, Z.; Weidong, W.; Xueming, W.; Xinlu, C.; Dawei, Y.; Changle, S.; Liping, P.; Yuying, W.; Li, B., The Investigation of $\mathrm{NbO}_{2}$ and $\mathrm{Nb}_{2} \mathrm{O}_{5}$ Electronic Structure by XPS, UPS and First Principles Methods. Surf. Interface Anal. 2013, 45, 1206-1210.

12. Luo, Y.; Wang, P.; Ma, L. P.; Cheng, H. M., Hydrogen Sorption Kinetics of $\mathrm{MgH}_{2}$ Catalyzed with $\mathrm{NbF}_{5}$. J. Alloys Compd. 2008, 453, 138-142.

13. Dacca, A.; Gemme, G.; Mattera, L.; Parodi, R., XPS Analysis of the Surface Composition of Niobium for Superconducting RF Cavities. Appl. Surf. Sci. 1998, 126, 219-230.

14. Jayaweera, P. M.; Quah, E. L.; Idriss, H., Photoreaction of Ethanol on $\mathrm{TiO}_{2}(110)$ SingleCrystal Surface. J. Phys. Chem. C 2007, 111, 1764-1769.

15. Romero, R.; Ramos-Barrado, J. R.; Martin, F.; Leinen, D., $\mathrm{Nb}_{2} \mathrm{O}_{5}$ Thin Films Obtained by Chemical Spray Pyrolysis. Surf. Interface Anal. 2004, 36, 888-891.

16. Chen, L.; Sun, Q. Q.; Gu, J. J.; Xu, Y.; Ding, S. J.; Zhang, D. W., Bipolar Resistive Switching Characteristics of Atomic Layer Deposited $\mathrm{Nb}_{2} \mathrm{O}_{5}$ Thin Films for Nonvolatile Memory Application. Current Applied Physics 2011, 11, 849-852.

17. Guo, S. Q.; Zhang, X.; Zhou, Z.; Gao, G. D.; Liu, L., Facile Preparation of Hierarchical $\mathrm{Nb}_{2} \mathrm{O}_{5}$ Microspheres with Photocatalytic Activities and Electrochemical Properties. Journal of Materials Chemistry A 2014, 2, 9236-9243.

18. Beamson, G.; Briggs, D., High Resolution XPS of Organic Polymers: The Scienta ESCA300 Database. Wiley: 1992.

19. Gulina, L.; Tolstoy, V.; Kasatkin, I.; Murin, I., Facile Synthesis of Scandium Fluoride Oriented Single-Crystalline Rods and Urchin-like Structures by a Gas-Solution Interface Technique. CrystEngComm 2017, 19, 5412-5416.

20. Nakayama, M.; Fukuda, M.; Konishi, S.; Tonosaki, T., Effects of Reaction Parameters on the Electrochemical Formation of Multilayer Films Composed of Manganese Oxides and Tetra-alkylammonium Ions. J. Mater. Res. 2006, 21, 3152-3160. 